\title{
A New Method for Determining the Design Values of Wave-Induced Hull Girder Loads Acting on Ships
}

\author{
Jeom Kee Paik ${ }^{\mathrm{a}, \mathrm{b}, \mathrm{c}^{*}}$, Dong Hun Lee ${ }^{\mathrm{a}}$, Sang Jin Kim ${ }^{\mathrm{b}}$, Giles Thomas ${ }^{\mathrm{c}}$ and Ming Ma ${ }^{\mathrm{d}}$ \\ ${ }^{a}$ Department of Naval Architecture and Ocean Engineering, Pusan National University, Busan 46241, \\ Republic of Korea \\ ${ }^{b}$ The International Centre for Advanced Safety Studies (The Lloyd's Register Foundation Research \\ Centre of Excellence), Busan 46241, Republic of Korea \\ ${ }^{c}$ Department of Mechanical Engineering, University College London, London WC1E 7JE, UK \\ ${ }^{d}$ MAESTRO Marine LLC, Maryland 21639, USA \\ *Corresponding author. J.K. Paik. (Email) jeompaik@gmail.com
}

\begin{abstract}
This paper presents a new methodology to determine the design values of wave-induced hull girder loads acting on ships. The method is based on probabilistic approaches associated with selected scenarios that represent possible events in terms of the ship's functionality, operation and environment. As illustrative examples, the method is used to determine the design values of wave-induced vertical bending moments for as-built ships (a VLCC class tanker, a 9,300 TEU containership and a 22,000 TEU containership) and a hypothetical 25,000 TEU containership. The probabilities of exceedance for wave loads acting on ships are discussed in association with the design load values determined from classification society rules. It is found that both the class rule method and the present method are in good agreement for the considered example ships. The present methodology can of course be applied to determine other components of design wave loads such as horizontal bending moments and torsional moments.
\end{abstract}

Keywords: Ship structural loads; Design wave loads; Selection of wave scenarios; Ship motion analysis; Probability of exceedance; Wave statistical database

\section{Introduction}

The international shipping industry desires to economize by lowering operating expenditures as well as building costs, and ship sizes have thus increased substantially in recent years and with them the capacity to carry more cargo for the same or lower costs. For example, container vessels have doubled in size over the last decade as shown in Figure 1 (Paik 2015), while total vessel costs per transported container have declined by approximately a third. The ultra-large containerships carrying more than 24,000 TEU have never been built, and thus a lot of technical challenges associated with wave-induced hull girder loads, among other factors, are relevant to be resolved for structural analysis and design of new types of ships in association with structural integrity and safety. Figure 2 shows structural failure of containerships, followed by total loss or catching fires before sinking.

In fact, the design values of wave-induced hull girder loads acting on ships are required to be determined for ship structural analysis and design (Hughes and Paik 2013). Classification society rules expressed in closed-form equations, as a function of principal dimensions and operational parameters, are useful for this purpose. However, such design equations are sometimes uncertain to adopt new types of ships, and direct computations using seakeeping analysis methods are inevitably required to determine the design values. Challenges still remain unresolved because environmental and operational conditions are fully probabilistic, and prescriptive approaches are insufficient to characterise ship motions in waves.

A state-of-the-art review is not included in this paper, since many useful contributions to this topic are already available in the literature or text books, e.g. refer to Chapter 4 of Ship Structural Analysis and Design (Hughes and Paik 2013). Recently, Temarel et al. (2016) reviewed the progress and challenges associated with the methods for evaluating the wave-induced loads acting on ships in terms of analytical, numerical and experimental approaches. 


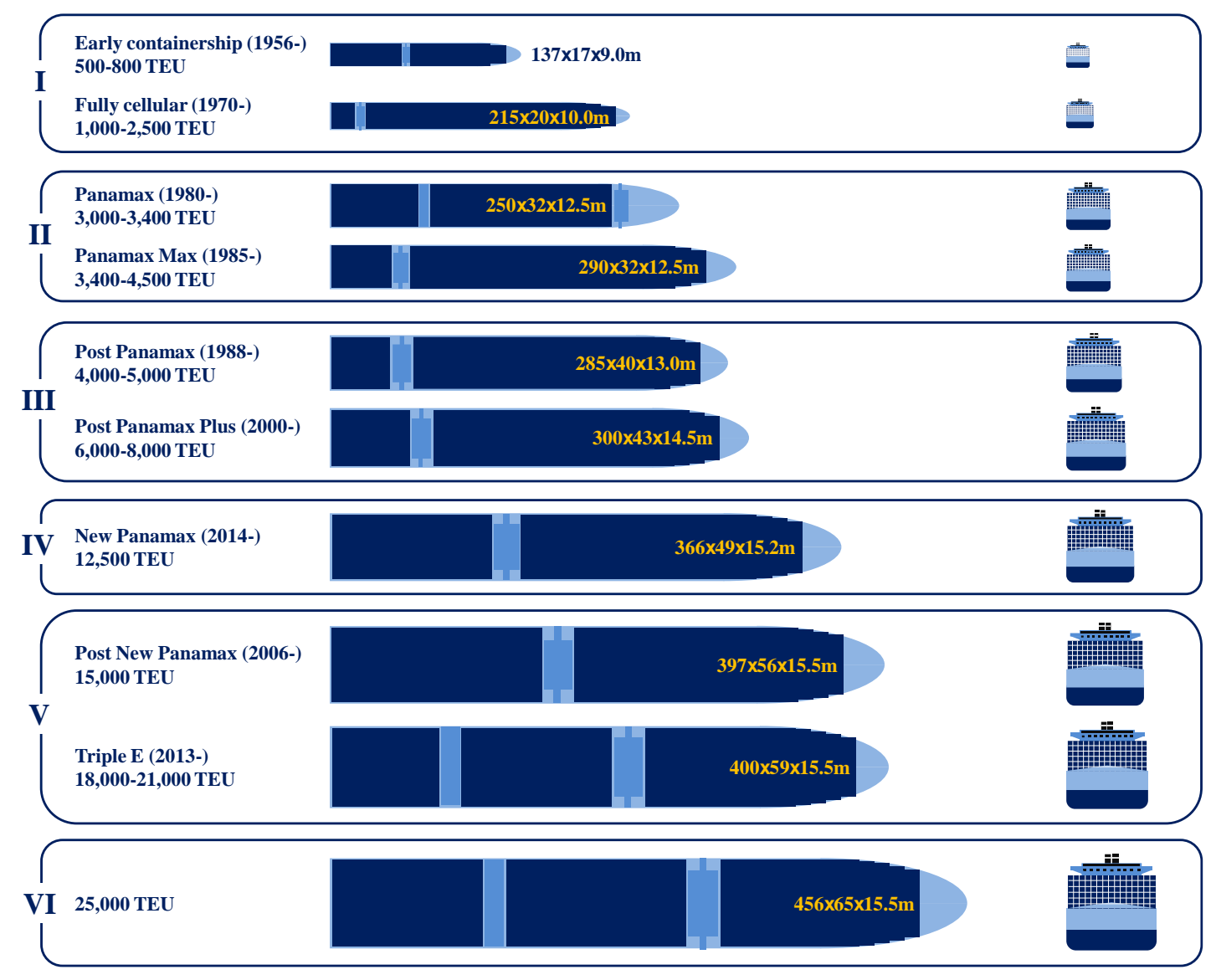

Figure 1. Change of the containership size (Paik 2015).
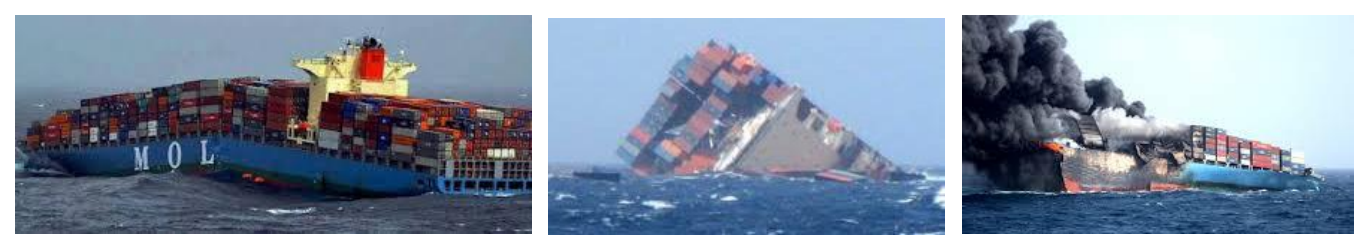

Figure 2. Accidents in containerships.

Two approaches may be considered to determine the design values of structural loads as shown in Figure 3. One approach as presented on the left side flow of Figure 3 is to define a "design action" representing the structural actions and the design values of structural loads are determined by the motion and load analysis of the structures at the predefined design actions. This approach is useful to determine the design loads once the design actions are defined properly. However, it is challenging to define the design actions that must represent the structural actions during the entire period of life time. Another approach as presented on the right side flow of Figure 3, which is firstly proposed in the present paper to overcome these difficulties, is to start with the selection of select realistic scenarios for structural events instead of defining the design actions. The motion and load analyses are undertaken for each of selected event scenarios. The relationship between the probability of exceedance versus structural loads can be established based on the computations for the selected event scenarios. With the acceptance criteria which are constant for the similar types of structural systems, the structural design loads can be defined consistently.

In shipbuilding industry, the wave-induced hull girder loads acting on ships have traditionally been determined based on 'design waves' (design actions) which can be evaluated by ship motion and load analysis to define the nominal values of wave-induced loads. To overcome the above-mentioned difficulties in the traditional design-wave based approach, this paper presents a new method to determine the design values of wave-induced hull girder loads acting on ships. The developed method 
is essentially based on probabilistic approaches where a set of scenarios covering the structural actions are selected probabilistically in terms of the parameters of influence. Based on the ship motion and load analyses, the probability of exceedance curve is established and the design loads are determined.

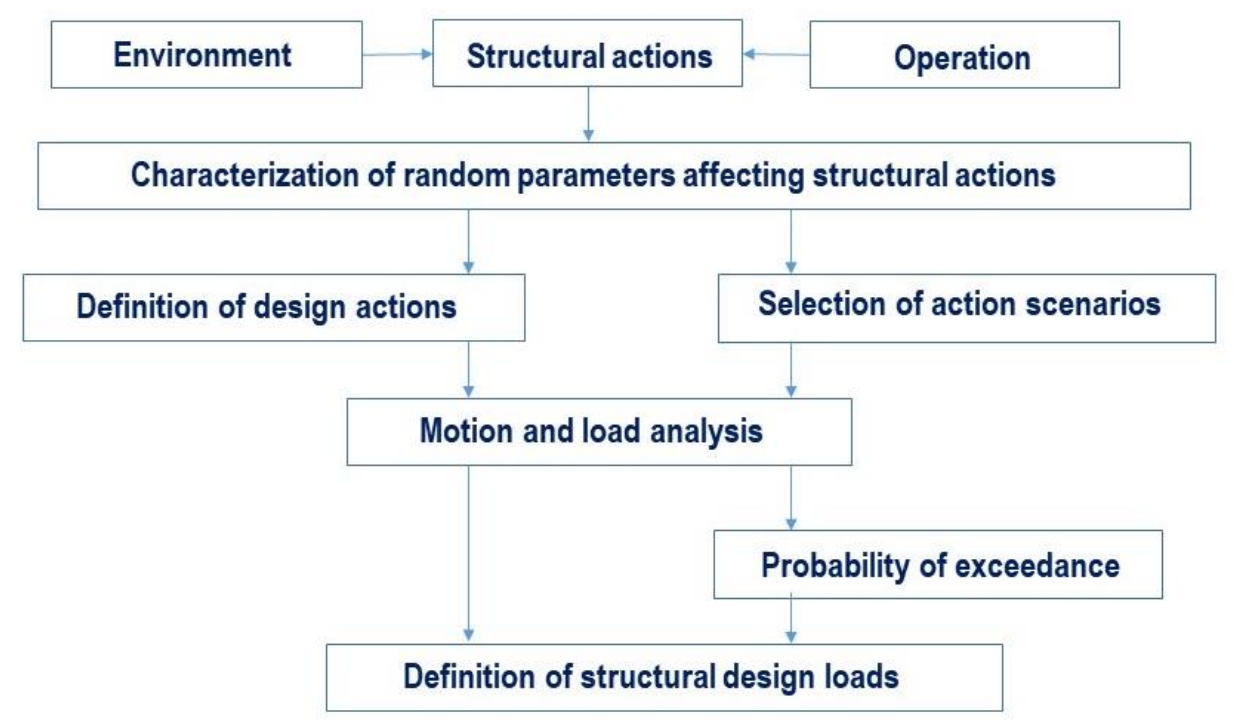

Figure 3. Two approaches for defining the structural design loads.

In the proposed method, the probability of exceedance is assessed for selected scenarios representing all possible motions of ships associated with waves. Seakeeping motion and load analyses for each of the individual scenarios can be performed using commercialized computer software taking into account the nonlinear effects due to irregular sea states and operating speed, etc. In the applied examples of the present paper, however, the MAESTRO computer program (MAESTRO 2018) is used with linear frequency domain hydrodynamic strip theory associated with a 3-dimensional finite element method model (Ma et al. 2012, Zhao et al. 2013, Zhao and Ma 2016, Prini et al. 2016), while the nonlinear correction is made based on ABS's DLA procedure (ABS 2015). This is for the purpose of simplicity where the present paper aims at demonstrating the applicability of the proposed method to determine the wave-induced hull girder loads acting on ships. Further studies are recommended with the nonlinear effects in this regard although the proposed procedure is still applicable.

To demonstrate the applicability of the proposed method, the design values of wave-induced hull girder loads are determined for as-built ships including a VLCC class tanker, a 9,300 TEU containership and a 22,000 TEU containership which are in operation. The magnitudes of the probability of exceedance assigned for as-built ships, in terms of wave-induced vertical bending moments, are discussed in relation to the design wave-induced load values determined from IACS rules. The developed method is also applied to a hypothetical 25,000 TEU containership to determine the design values of the wave-induced vertical bending moments.

\section{Proposed method for determining design wave-induced loads acting on ships with a focus on wave-induced vertical bending moments for an as-built VLCC class tanker}

Figure 4 shows the proposed procedure for determining the design values of wave-induced loads on ships at sea, which is based on fully probabilistic approaches. Once the data of the target ship is defined in terms of hull form, loading condition and load water line, as well as principal dimensions, structural geometry, material properties and equipment masses, a set of credible wave event scenarios is selected by a sampling technique in association with random parameters affecting ship motions in waves such as significant wave height (or wave amplitude), zero crossing wave period (converting to wave length) and wave heading angle together with wave phase angle. This is in contrast to traditional methods in industry, where probabilistic approaches are applied to define design waves and the design values of wave-induced hull girder loads are predicted by seakeeping motion and load analysis in association with the predefined design waves. In the new method, the ship motion and load analyses are undertaken for each of individual wave event scenarios, giving the relationship between the wave probability of exceedance versus the hull girder loads. The design values of wave-induced hull girder 
loads can then be determined as per the acceptance criteria associated with the "as-low-as-reasonablypracticable (ALARP)" level.

To describe the proposed procedure, a VLCC class double hull oil tanker is considered as an example. The focus is on wave-induced vertical moments as other hull girder load components such as shear forces and torsional moments can be determined in a similar way. Table 1 provides the principal dimensions of the example ship. Figure 5 shows the three-dimensional Finite Element Analysis (FEA) model for the entire ship which should assign details of hull form precisely. In this model, the centres of gravity and buoyancy need to be assigned properly, together with the subsequent trim condition, since the weight and buoyancy distributions are included. The FEA model here is not for the purpose of structural analysis, and thus it is not necessary to assign details of structural scantlings.

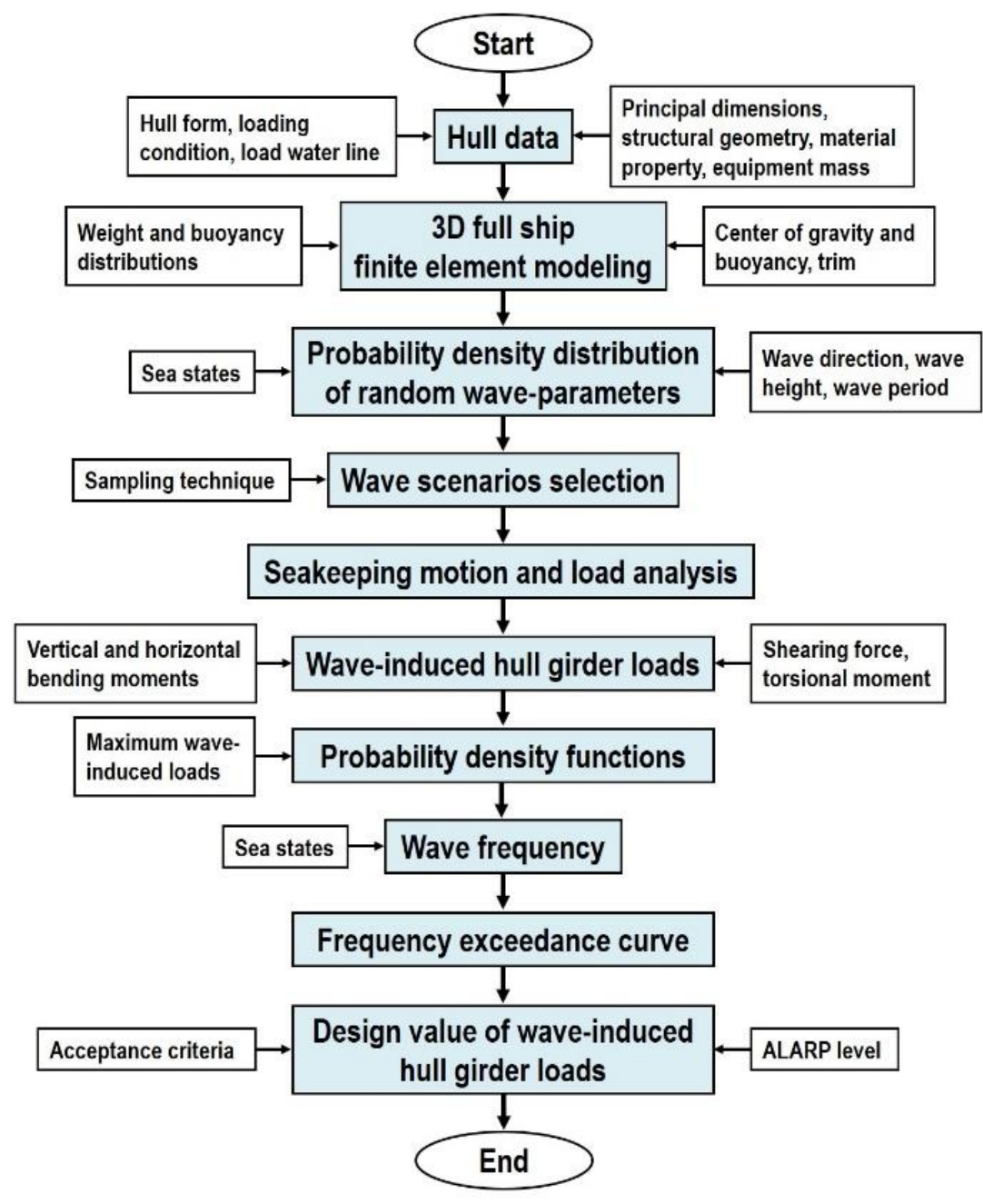

Figure 4. Proposed procedure for determining the design values of wave-induced loads on ships at sea.

Structural loads on ships at sea are predominantly affected by waves; the following three dominant random parameters affecting the wave-induced hull girder loads on ships can be considered, which are all random variables:

- $\quad$ Significant wave height, $H_{s}$

- Zero crossing wave period, $T_{z}$ (or wave length $\lambda$ )

- Wave direction (or angle), $\theta$

It is noted that the three wave parameters considered here are for the illustrative purpose of the present methodology, and they can be refined or more parameters (e.g., ship speed, wind speed, wind direction, current speed, current direction,) as more wave statistical database becomes available. 
A relationship between the spectral peak wave period $T_{z}$ and the wave length $\lambda$ may be defined as follows (Chakrabarti 2005):

$$
\lambda=\frac{g T_{z}^{2}}{2 \pi}
$$

where $g$ is the gravitational acceleration which is taken as $9.8 \mathrm{~m} / \mathrm{s}^{2}$. Equation (1) is useful for the seakeeping motion analysis where the wave length should be defined in advance. Again, other expressions rather than Equation (1) can be used as they are confirmed to be adequate with more wave statistical database.

Table 1. Principal dimensions of the example VLCC class double hull oil tanker.

\begin{tabular}{ll}
\hline Parameter & Dimension \\
\hline Length between perpendiculars $\left(L_{B P}\right)$ & $309.3 \mathrm{~m}$ \\
Length on summer load waterline $\left(L_{L W L}\right)$ & $317.9 \mathrm{~m}$ \\
Breadth $(B)$ & $60.0 \mathrm{~m}$ \\
Depth $(D)$ & $30.0 \mathrm{~m}$ \\
Design draught $(d)$ & $21.6 \mathrm{~m}$ \\
Block coefficient $\left(C_{b}\right)$ & 0.81 \\
Design speed & $16.0 \mathrm{knot}$ \\
\hline
\end{tabular}

Offshore installations, for oil and gas production or marine renewable energy, are stationary and therefore operated at a specific location that is governed by site-specific meteological oceanographical (metocean) conditions. In this regard, the structural loads on offshore installations are determined for the site-specific metocean conditions that should include not only waves but also wind and currents.

In contrast, ships are moving to transport cargo or to patrol for security purposes, perhaps in a specific ocean. For example, shipping companies may build merchant cargo ships aiming to operating them only on a predesignated route, e.g. the Pacific Ocean between Korea and United States. Some naval ships may operate only in the waters of the host country, but other naval ships may operate globally in non-predesignated route conditions. If the trading routes of ships are specifically designated, then the structural loads induced by waves can also be determined by the route-specific sea states similar to the offshore installations associated with site-specific metocean conditions.

However, in reality a ship owner may wish to sell a ship on the second-hand market and the new owners may want to use the purchased ship on a different ocean which may have harsher environmental conditions than the route considered for the original design. In this regard, classification societies have enforced the application of rules that all ocean-going ships are to be designed on the basis of the environmental conditions associated with the harshest ocean worldwide, which is the North Atlantic Ocean (IACS 2001). Table 2 provides the probability of sea states in the North Atlantic Ocean derived from BMT's Global Wave Statistics (www.bmt.org).

The probabilistic density distribution characteristics of the random wave parameters can be identified once the database of sea states is available. As an illustrative purpose of the present methodology, this paper adopts the following probabilistic functions which were formulated based on the sea states of the North Atlantic Ocean (Walck 2007):

For the significant wave height $H_{s}$ in $\mathrm{m}$, a two-parameter Weibull distribution is adopted:

$$
f(x)=\frac{\beta}{\alpha}\left(\frac{x}{\alpha}\right)^{\beta-1} \exp \left[-\left(\frac{x}{\alpha}\right)^{\beta}\right]
$$

where $\alpha=1.914$ and $\beta=3.854$.

For the zero crossing wave period $T_{z}$ in s, a normal distribution is adopted: 


$$
f(x)=\frac{1}{\sigma \sqrt{2 \pi}} \exp \left[\frac{-(x-\mu)^{2}}{2 \sigma^{2}}\right]
$$

where $\mu=8.862$ and $\sigma=1.638$.

For the wave direction (angle) $\theta$ in deg., a constant function is adopted:

$$
f(x)=0.002778
$$

It is noted that the wave direction is assumed to be equally distributed for the present specific example, while the significant wave height and the wave period are probabilistically characterised in accordance with the sea states in the North Atlantic Ocean. Once the probability density distributions of random variables are all characterised with the relevant functions, a sampling technique is applied to select a set of wave event scenarios using a probabilistic procedure as presented in Figure 6. In the present study, a total of 100 scenarios have been selected by the Latin hypercube sampling technique, although more scenarios may of course help to better represent the possible wave events. For the details of the wave scenarios selection, Youssef and Paik (2018) and Paik (2019) may be referred to. Table 3 indicates the 100 wave event scenarios selected. Figure 7 shows the formulated probability density functions of the three wave parameters. It is confirmed that a total of 100 scenarios may be sufficient, as proven in Figure 8. Dots or points shown in Figure 8(a) indicate the interpolations or extrapolations of significant wave height and period associated with wave scenarios.

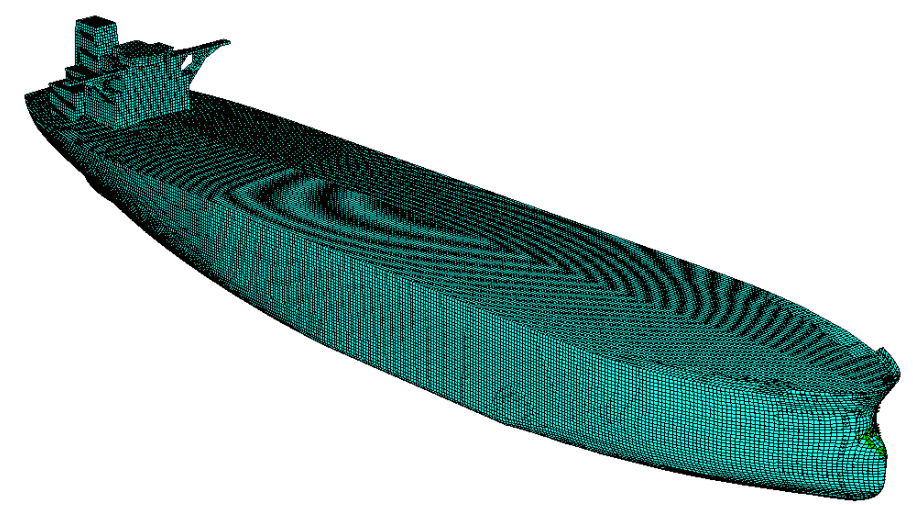

(a) Overall view

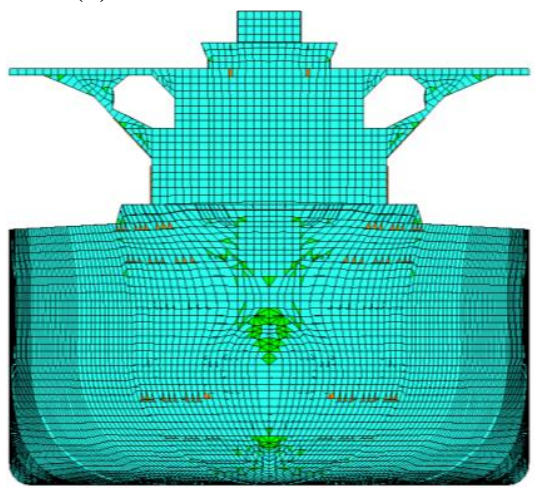

(b) Body plan view

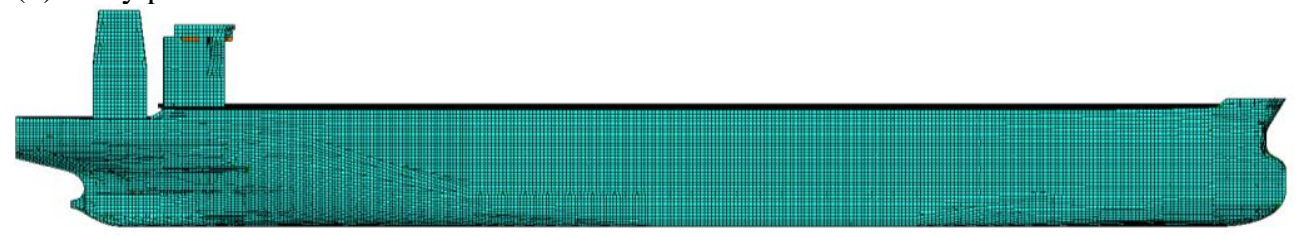

(c) Profile view 


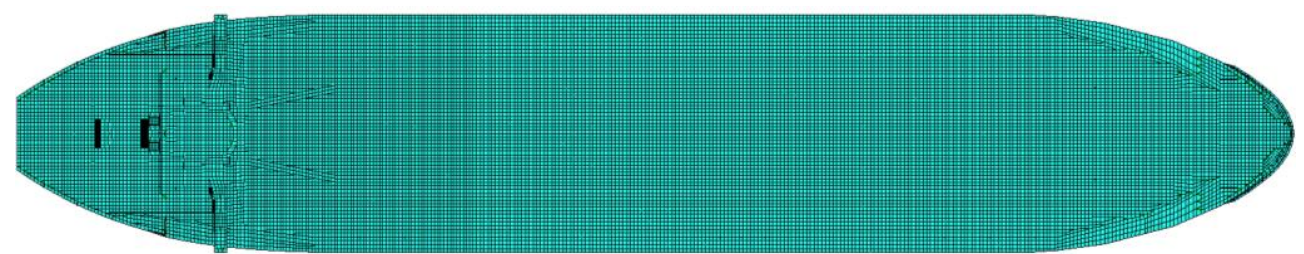

(d) Plan view

Figure 5. Three-dimensional FEA model of the example VLCC class double hull oil tanker.

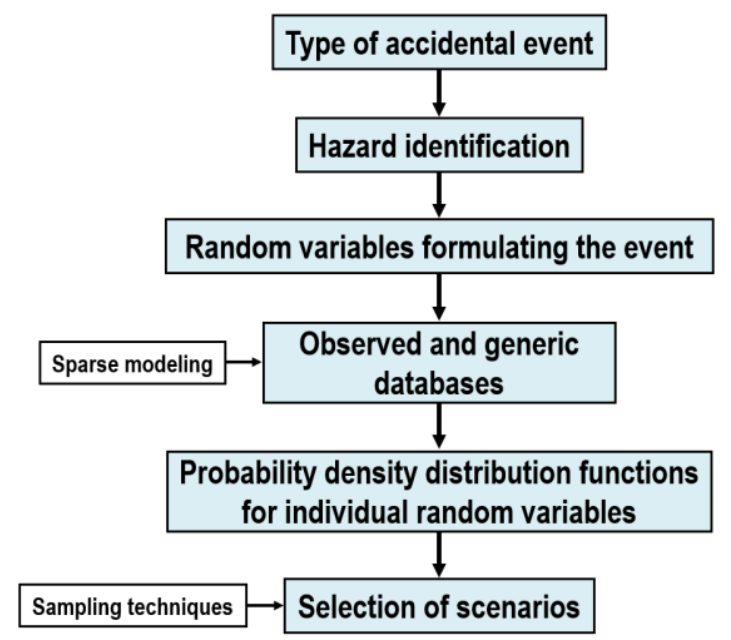

Figure 6. A probabilistic procedure for selecting event scenarios.

Table 2. The probability of wave encounters associated with sea states in the North Atlantic Ocean ( $H_{s}$ in meter and $T_{z}$ in second).

\begin{tabular}{|c|c|c|c|c|c|c|c|c|c|c|c|c|c|c|c|c|c|c|c|}
\hline$H_{s} / T_{z}$ & 1.5 & 2.5 & 3.5 & 4.5 & 5.5 & 6.5 & 7.5 & 8.5 & 9.5 & 10.5 & 11.5 & 12.5 & 13.5 & 14.5 & 15.5 & 16.5 & 17.5 & 18.5 & Sum \\
\hline 0.5 & 0.0 & 0.0 & 1.3 & 133.7 & 865.6 & 1186.0 & 634.2 & 186.3 & 36.9 & 5.6 & 0.7 & 0.1 & 0.0 & 0.0 & 0.0 & 0.0 & 0.0 & 0.0 & 3050 \\
\hline 1.5 & 0.0 & 0.0 & 0.0 & 29.3 & 986.0 & 4976.0 & 7738.0 & 5569.7 & 2375.7 & 703.5 & 160.7 & 30.5 & 5.1 & 0.8 & 0.1 & 0.0 & 0.0 & 0.0 & 22575 \\
\hline 2.5 & 0.0 & 0.0 & 0.0 & 2.2 & 197.5 & 2158.8 & 6230.0 & 7449.5 & 4860.4 & 2066.0 & 644.5 & 160.2 & 33.7 & 6.3 & 1.1 & 0.2 & 0.0 & 0.0 & 23810 \\
\hline 3.5 & 0.0 & 0.0 & 0.0 & 0.2 & 34.9 & 695.5 & 3226.5 & 5675.0 & 5099.1 & 2838.0 & 1114.1 & 337.7 & 84.3 & 18.2 & 3.5 & 0.6 & 0.1 & 0.0 & 19128 \\
\hline 4.5 & 0.0 & 0.0 & 0.0 & 0.0 & 6.0 & 196.1 & 1354.3 & 3288.5 & 3857.5 & 2685.5 & 1275.2 & 455.1 & 130.9 & 31.9 & 6.9 & 1.3 & 0.2 & 0.0 & 13289 \\
\hline 5.5 & 0.0 & 0.0 & 0.0 & 0.0 & 1.0 & 51.0 & 498.4 & 1602.9 & 2372.7 & 2008.3 & 1126.0 & 463.6 & 150.9 & 41.0 & 9.7 & 2.1 & 0.4 & 0.1 & 8328 \\
\hline 6.5 & 0.0 & 0.0 & 0.0 & 0.0 & 0.2 & 12.6 & 167.0 & 690.3 & 1257.9 & 1268.6 & 825.9 & 386.8 & 140.8 & 42.2 & 10.9 & 2.5 & 0.5 & 0.1 & 4806 \\
\hline 7.5 & 0.0 & 0.0 & 0.0 & 0.0 & 0.0 & 3.0 & 52.1 & 270.1 & 594.4 & 703.2 & 524.9 & 276.7 & 111.7 & 36.7 & 10.2 & 2.5 & 0.6 & 0.1 & 2586 \\
\hline 8.5 & 0.0 & 0.0 & 0.0 & 0.0 & 0.0 & 0.7 & 15.4 & 97.9 & 255.9 & 350.6 & 296.9 & 174.6 & 77.6 & 27.7 & 8.4 & 2.2 & 0.5 & 0.1 & 1309 \\
\hline 9.5 & 0.0 & 0.0 & 0.0 & 0.0 & 0.0 & 0.2 & 4.3 & 33.2 & 101.7 & 159.9 & 152.2 & 99.2 & 48.3 & 18.7 & 6.1 & 1.7 & 0.4 & 0.1 & 626 \\
\hline 10.5 & 0.0 & 0.0 & 0.0 & 0.0 & 0.0 & 0.0 & 1.2 & 10.7 & 37.9 & 67.5 & 71.7 & 51.5 & 27.3 & 11.4 & 4.0 & 1.2 & 0.3 & 0.1 & 285 \\
\hline 11.5 & 0.0 & 0.0 & 0.0 & 0.0 & 0.0 & 0.0 & 0.3 & 3.3 & 13.3 & 26.6 & 31.4 & 24.7 & 14.2 & 6.4 & 2.4 & 0.7 & 0.2 & 0.1 & 124 \\
\hline 12.5 & 0.0 & 0.0 & 0.0 & 0.0 & 0.0 & 0.0 & 0.1 & 1.0 & 4.4 & 9.9 & 12.8 & 11.0 & 6.8 & 3.3 & 1.3 & 0.4 & 0.1 & 0.0 & 51 \\
\hline 13.5 & 0.0 & 0.0 & 0.0 & 0.0 & 0.0 & 0.0 & 0.0 & 0.3 & 1.4 & 3.5 & 5.0 & 4.6 & 3.1 & 1.6 & 0.7 & 0.2 & 0.1 & 0.0 & 21 \\
\hline 14.5 & 0.0 & 0.0 & 0.0 & 0.0 & 0.0 & 0.0 & 0.0 & 0.1 & 0.4 & 1.2 & 1.8 & 1.8 & 1.3 & 0.7 & 0.3 & 0.1 & 0.0 & 0.0 & 8 \\
\hline 15.5 & 0.0 & 0.0 & 0.0 & 0.0 & 0.0 & 0.0 & 0.0 & 0.0 & 0.1 & 0.4 & 0.6 & 0.7 & 0.5 & 0.3 & 0.1 & 0.1 & 0.0 & 0.0 & 3 \\
\hline 16.5 & 0.0 & 0.0 & 0.0 & 0.0 & 0.0 & 0.0 & 0.0 & 0.0 & 0.0 & 0.1 & 0.2 & 0.2 & 0.2 & 0.1 & 0.1 & 0.0 & 0.0 & 0.0 & 1 \\
\hline Sum & 0 & 0 & 1 & 165 & 2091 & 9280 & 19922 & 24879 & 20870 & 12898 & 6245 & 2479 & 837 & 247 & 66 & 16 & 3 & 1 & $1 \times 10^{5}$ \\
\hline
\end{tabular}

Table 3. A total of 100 wave event scenarios selected by the Latin Hypercube sampling technique with Equation (2).

\begin{tabular}{llll|llll}
\hline $\begin{array}{l}\text { Scenario } \\
\text { No. }\end{array}$ & $H_{s}(\mathrm{~m})$ & $T_{z}(\mathrm{~s})$ & $\theta($ deg. $)$ & $\begin{array}{l}\text { Scenario } \\
\text { No. }\end{array}$ & $H_{s}(\mathrm{~m})$ & $T_{z}(\mathrm{~s})$ & $\theta(\mathrm{deg})$. \\
\hline 1 & 2.693 & 8.555 & 167.4 & 51 & 1.521 & 8.299 & 120.6
\end{tabular}




\begin{tabular}{|c|c|c|c|c|c|c|c|}
\hline 2 & 2.228 & 6.897 & 45.0 & 52 & 3.767 & 6.087 & 286.2 \\
\hline 3 & 9.584 & 5.653 & 264.6 & 53 & 4.104 & 8.471 & 30.6 \\
\hline 4 & 7.691 & 10.278 & 325.8 & 54 & 2.369 & 6.616 & 185.4 \\
\hline 5 & 1.889 & 10.841 & 304.2 & 55 & 2.415 & 11.237 & 37.8 \\
\hline 6 & 0.564 & 11.362 & 311.4 & 56 & 3.609 & 8.597 & 55.8 \\
\hline 7 & 5.449 & 7.885 & 95.4 & 57 & 3.357 & 8.845 & 253.8 \\
\hline 8 & 8.275 & 11.125 & 109.8 & 58 & 4.045 & 5.896 & 73.8 \\
\hline 9 & 0.429 & 9.476 & 243.0 & 59 & 4.686 & 10.680 & 268.2 \\
\hline 10 & 2.647 & 9.847 & 343.8 & 60 & 4.993 & 5.304 & 88.2 \\
\hline 11 & 7.300 & 9.656 & 145.8 & 61 & 5.554 & 8.804 & 142.2 \\
\hline 12 & 7.000 & 10.758 & 27.0 & 62 & 4.545 & 10.467 & 91.8 \\
\hline 13 & 0.859 & 8.721 & 293.4 & 63 & 6.755 & 7.982 & 207.0 \\
\hline 14 & 4.834 & 8.968 & 351.0 & 64 & 0.772 & 10.219 & 84.6 \\
\hline 15 & 2.601 & 9.999 & 153.0 & 65 & 1.347 & 10.535 & 156.6 \\
\hline 16 & 1.684 & 9.176 & 149.4 & 66 & 4.615 & 8.886 & 99.0 \\
\hline 17 & 3.558 & 10.052 & 232.2 & 67 & 2.462 & 9.897 & 297.0 \\
\hline 18 & 3.456 & 11.502 & 300.6 & 68 & 3.162 & 9.260 & 250.2 \\
\hline 19 & 0.229 & 9.345 & 225.0 & 69 & 2.973 & 10.606 & 289.8 \\
\hline 20 & 2.879 & 8.927 & 174.6 & 70 & 1.576 & 6.717 & 127.8 \\
\hline 21 & 3.211 & 8.121 & 52.2 & 71 & 2.926 & 10.162 & 59.4 \\
\hline 22 & 2.740 & 8.166 & 235.8 & 72 & 1.787 & 12.495 & 315.0 \\
\hline 23 & 1.464 & 7.057 & 1.8 & 73 & 5.164 & 8.075 & 160.2 \\
\hline 24 & 3.661 & 7.130 & 131.4 & 74 & 3.067 & 10.402 & 16.2 \\
\hline 25 & 3.988 & 9.611 & 257.4 & 75 & 4.348 & 7.268 & 271.8 \\
\hline 26 & 3.714 & 6.506 & 102.6 & 76 & 5.665 & 12.119 & 203.4 \\
\hline 27 & 2.322 & 9.703 & 192.6 & 77 & 2.832 & 7.571 & 63.0 \\
\hline 28 & 3.020 & 4.539 & 81.0 & 78 & 2.555 & 7.785 & 124.2 \\
\hline 29 & 4.223 & 9.432 & 196.2 & 79 & 5.350 & 7.934 & 12.6 \\
\hline 30 & 1.157 & 6.384 & 41.4 & 80 & 2.085 & 8.211 & 189.0 \\
\hline 31 & 4.759 & 8.255 & 181.8 & 81 & 4.912 & 8.680 & 329.4 \\
\hline 32 & 2.508 & 13.314 & 199.8 & 82 & 2.133 & 9.565 & 228.6 \\
\hline 33 & 1.630 & 9.750 & 5.4 & 83 & 4.285 & 7.626 & 340.2 \\
\hline 34 & 3.115 & 11.023 & 48.6 & 84 & 5.077 & 9.218 & 23.4 \\
\hline 35 & 4.163 & 8.386 & 214.2 & 85 & 2.180 & 7.201 & 66.6 \\
\hline 36 & 4.412 & 7.733 & 318.6 & 86 & 1.987 & 8.762 & 77.4 \\
\hline 37 & 1.088 & 7.333 & 34.2 & 87 & 4.478 & 9.520 & 275.4 \\
\hline 38 & 6.197 & 6.246 & 135.0 & 88 & 3.821 & 6.979 & 113.4 \\
\hline 39 & 3.507 & 11.864 & 336.6 & 89 & 2.786 & 7.680 & 171.0 \\
\hline 40 & 6.545 & 9.051 & 163.8 & 90 & 1.223 & 9.948 & 138.6 \\
\hline 41 & 1.286 & 9.134 & 358.2 & 91 & 2.275 & 9.092 & 246.6 \\
\hline
\end{tabular}




\begin{tabular}{llll|llll}
42 & 1.838 & 8.513 & 106.2 & 92 & 0.675 & 8.343 & 307.8 \\
43 & 1.938 & 9.303 & 261.0 & 93 & 6.048 & 7.514 & 239.4 \\
44 & 5.784 & 9.009 & 217.8 & 94 & 1.736 & 7.835 & 322.2 \\
45 & 3.259 & 8.638 & 282.6 & 95 & 3.876 & 10.929 & 279.0 \\
46 & 5.255 & 11.666 & 333.0 & 96 & 3.932 & 7.456 & 19.8 \\
47 & 3.406 & 8.428 & 178.2 & 97 & 0.941 & 6.810 & 347.4 \\
48 & 1.017 & 9.388 & 221.4 & 98 & 1.406 & 7.395 & 354.6 \\
49 & 3.308 & 10.107 & 210.6 & 99 & 5.911 & 8.029 & 70.2 \\
50 & 6.361 & 9.798 & 9.0 & 100 & 2.036 & 10.339 & 117.0 \\
\hline
\end{tabular}
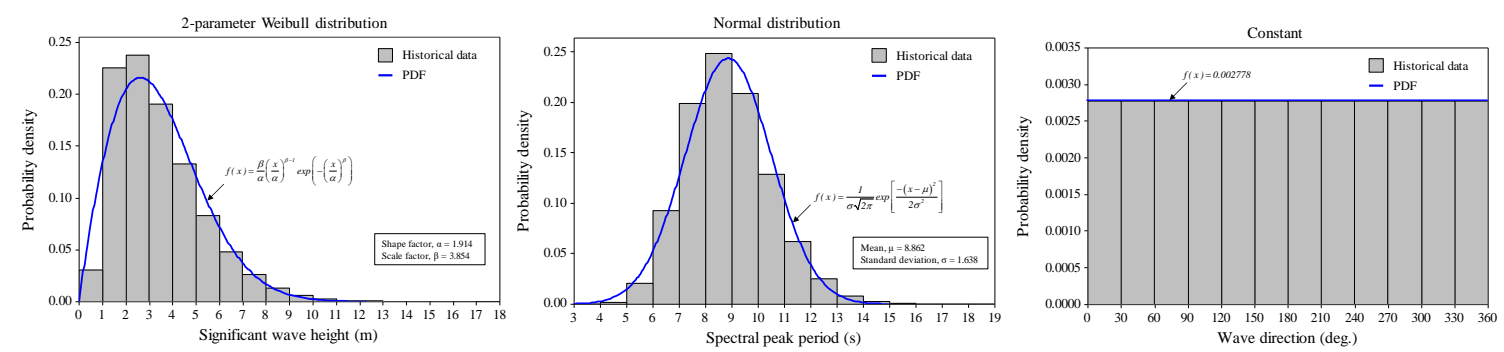

Figure 7. Formulation of the probability density functions (PDF) for the three wave parameters.

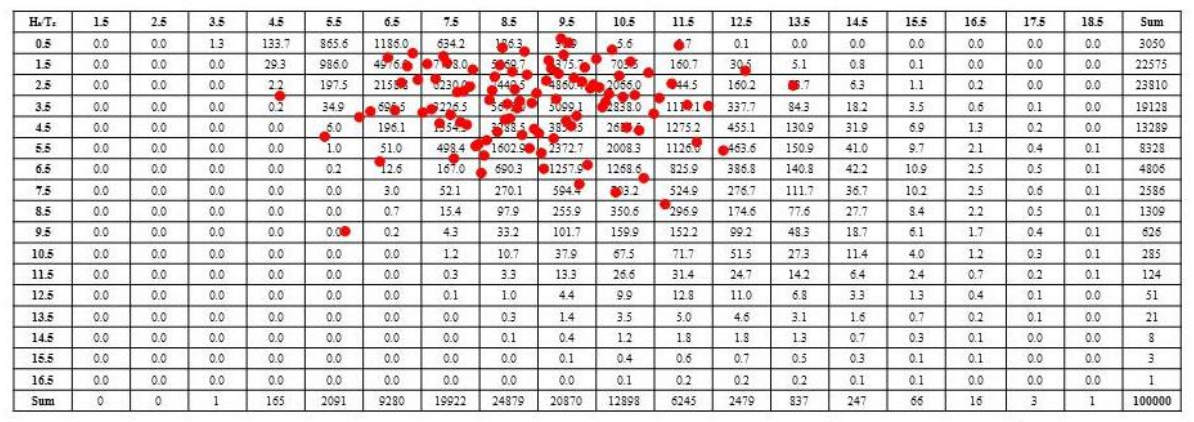

Figure 8(a). Interpolation and extrapolation distribution of the selected wave scenarios in the sea states database.
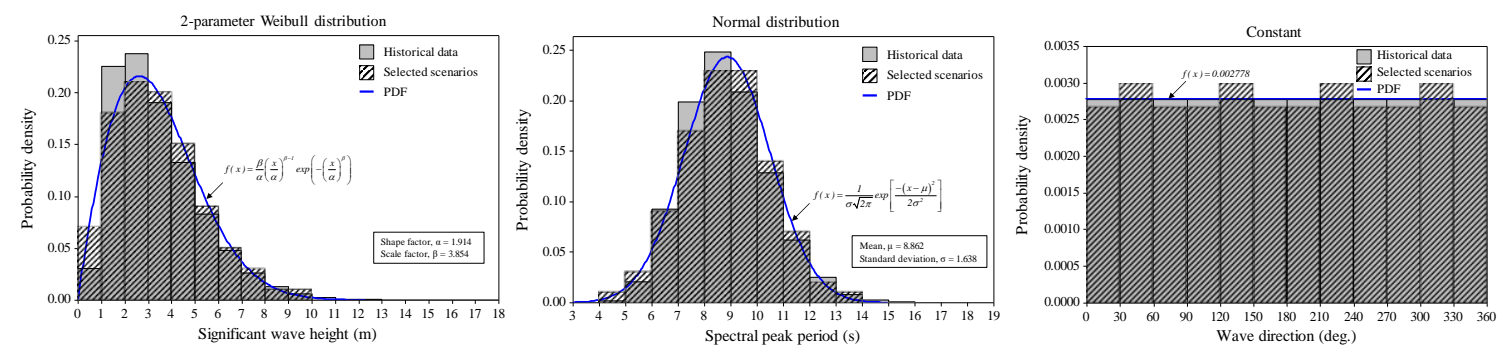

Figure 8(b). Confirmation of the selected event scenarios in accordance with the distributions of probability density functions (PDF) of the three wave parameters. 


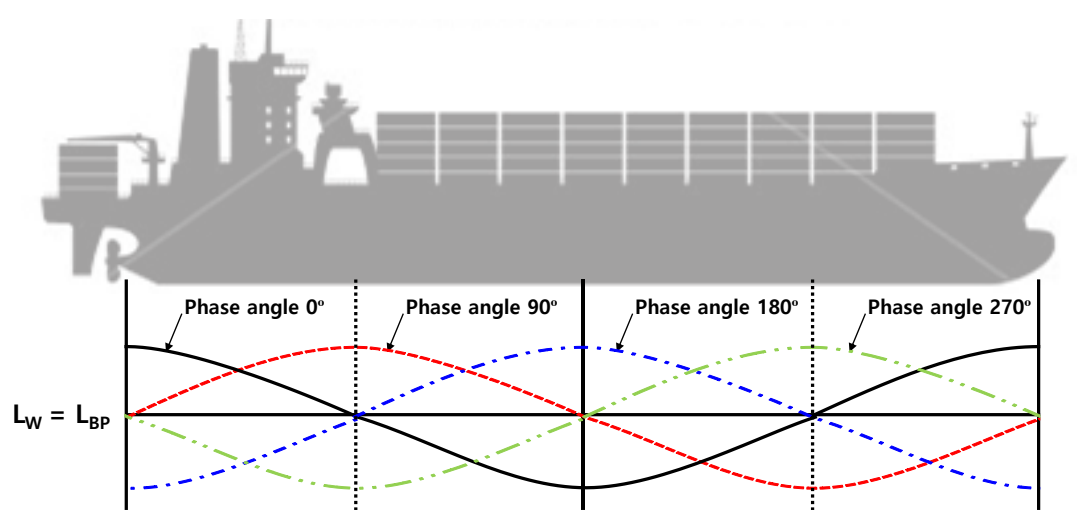

Figure 9. Definition of the wave phase angle when the wave length equals the ship length.

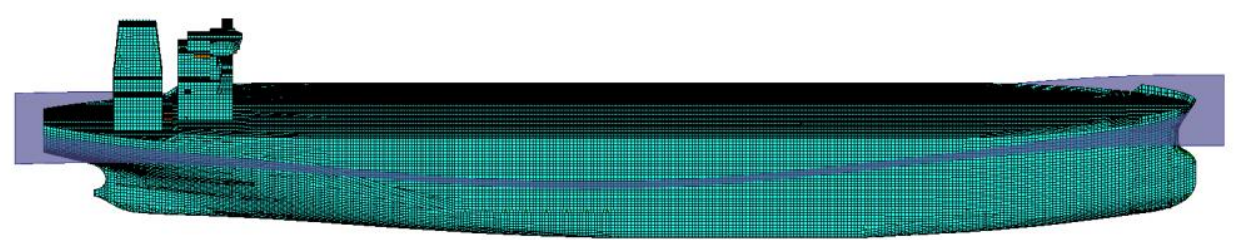

(a) Phase angle of $0 \mathrm{deg}$.

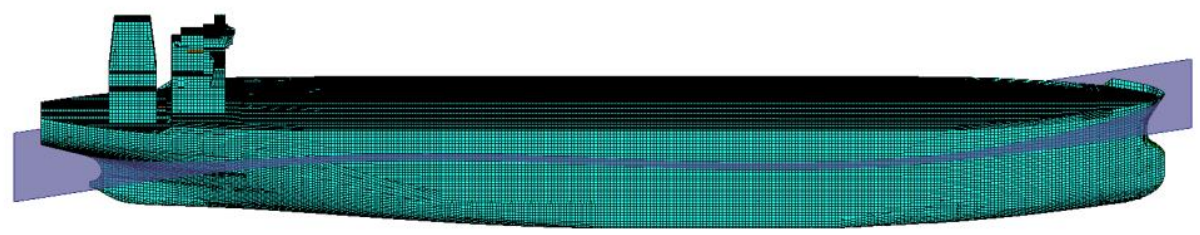

(b) Phase angle of $90 \mathrm{deg}$.

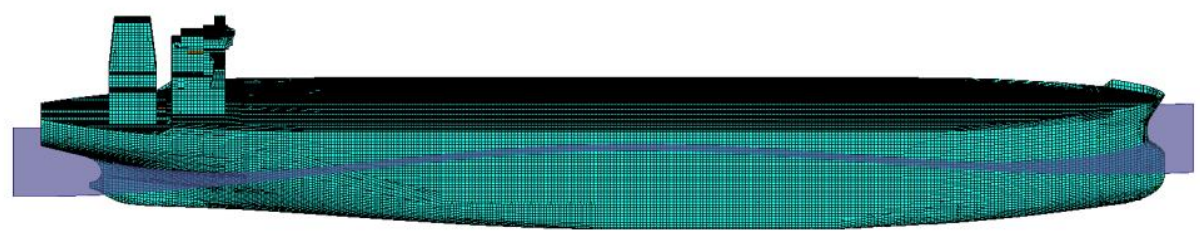

(c) Phase angle of $180 \mathrm{deg}$.

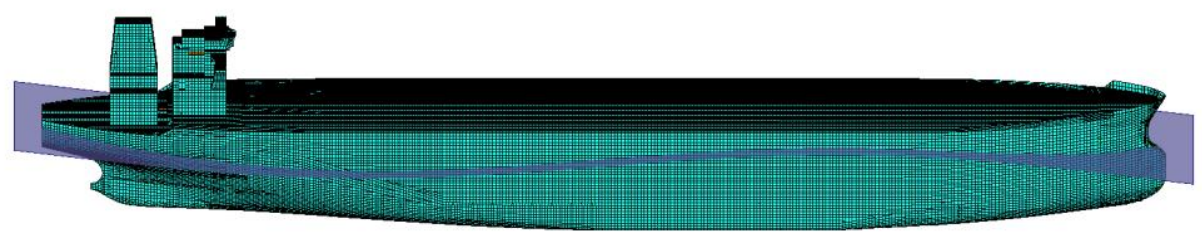

(d) Phase angle of $270 \mathrm{deg}$.

Figure 10. Illustrative wave elevations for different phase angles when the wave length equals the ship length. 


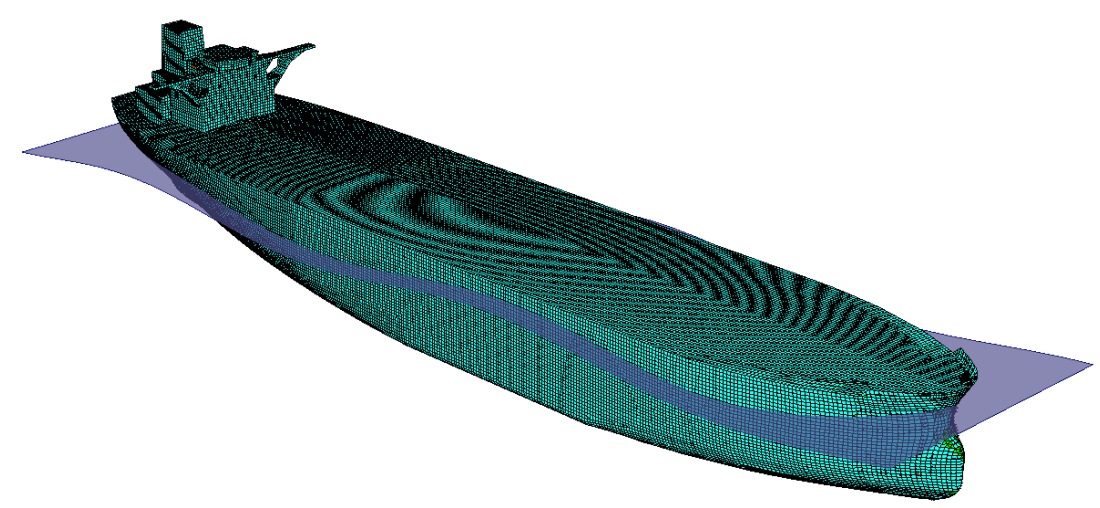

(a) Scenario 50 at wave direction of $9 \mathrm{deg}$. and phase angle of $90 \mathrm{deg}$.

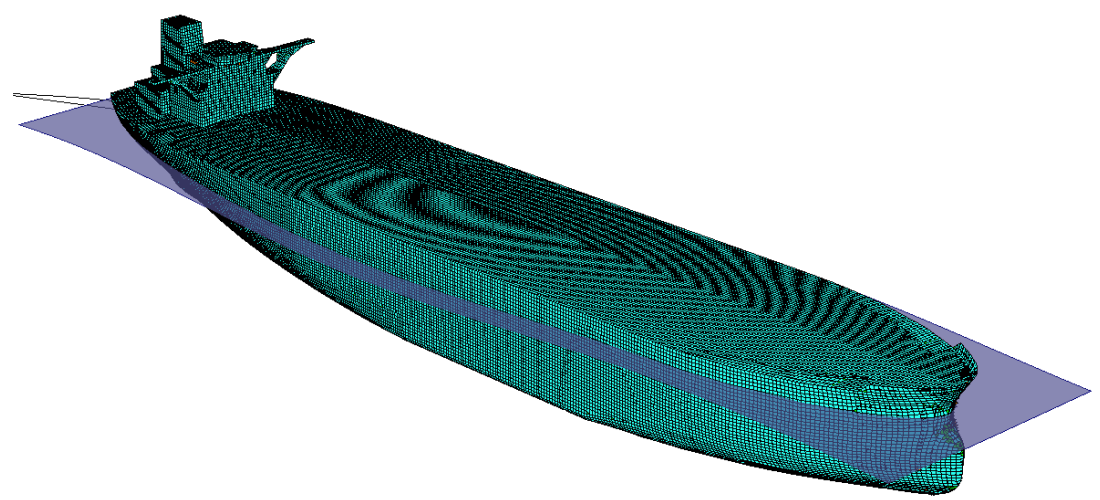

(b) Scenario 76 wave direction of $203.4 \mathrm{deg}$. and phase angle of $0 \mathrm{deg}$.

Figure 11. Wave elevations of selected scenarios for the example VLCC class tanker.

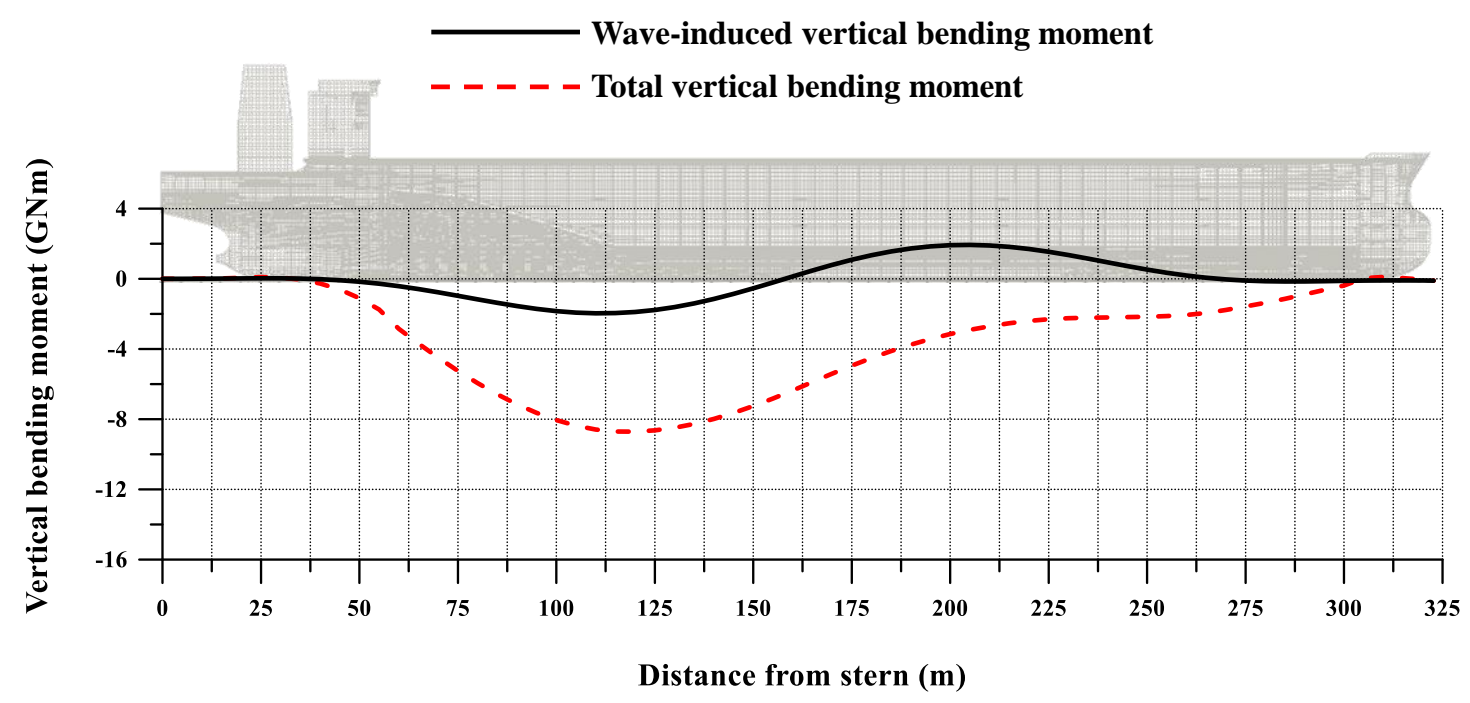

(a) Scenario 50 at wave direction of $9 \mathrm{deg}$. and phase angle of $90 \mathrm{deg}$. 


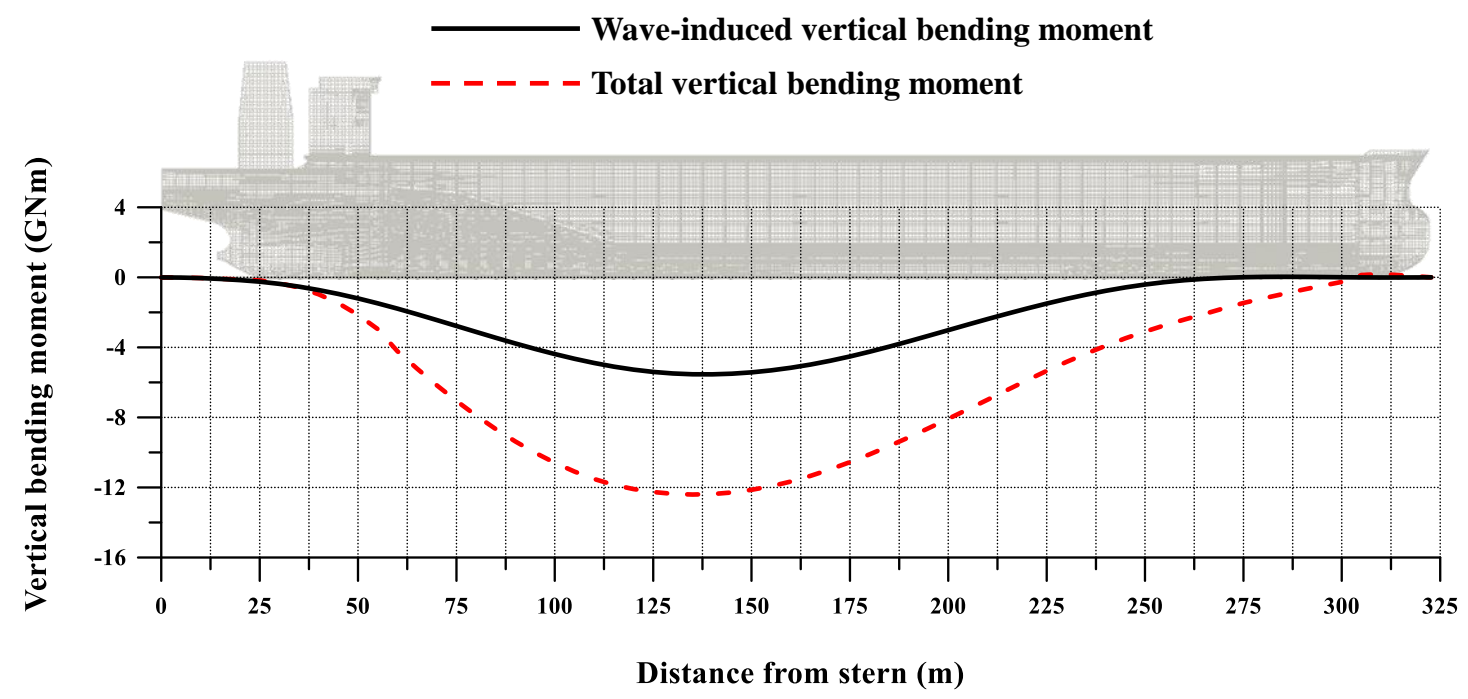

(b) Scenario 76 wave direction of $203.4 \mathrm{deg}$. and phase angle of $0 \mathrm{deg}$.

Figure 12. Distributions of total and wave-induced vertical bending moments of the example VLCC class tanker for selected wave scenarios.

Considering that the present paper aims at demonstrating the applicability of a new method to determine the wave-induced design loads, a simpler way of the ship motion and load analysis is applied without taking account of nonlinear effects due to irregular sea states or ship speed. For the event scenarios selected, therefore, regular wave simulations are undertaken at the full load condition in association with seakeeping load analysis using the MAESTRO computer program (MAESTRO 2018).

Four types of the phase angle are considered in the MAESTRO computations, as shown in Figure 9, where the wave length is illustrated to equal the ship length between perpendiculars. The maximum values of the wave-induced loads are determined from the four sets of computations by varying the phase angles. Figure 10 illustrates the wave elevations for different phase angles when the wave length equals the ship length, where the significant wave height is assumed to be $5 \mathrm{~m}$. Figure 11 shows the wave elevations of selected scenarios for the example VLCC class tanker. Figure 12 shows the distributions of the total and wave-induced vertical bending moments for selected wave scenarios along the example ship's length where the total moment is the sum of still-water and wave-induced moment components. Since the still-water bending moments for the example VLCC class tanker's hull are predominantly in sagging at the full load condition, only the sagging wave-induced bending moments are considered for calculating the total bending moments in the present study so that the sum of both still-water and wave-induced moment components are maximised.

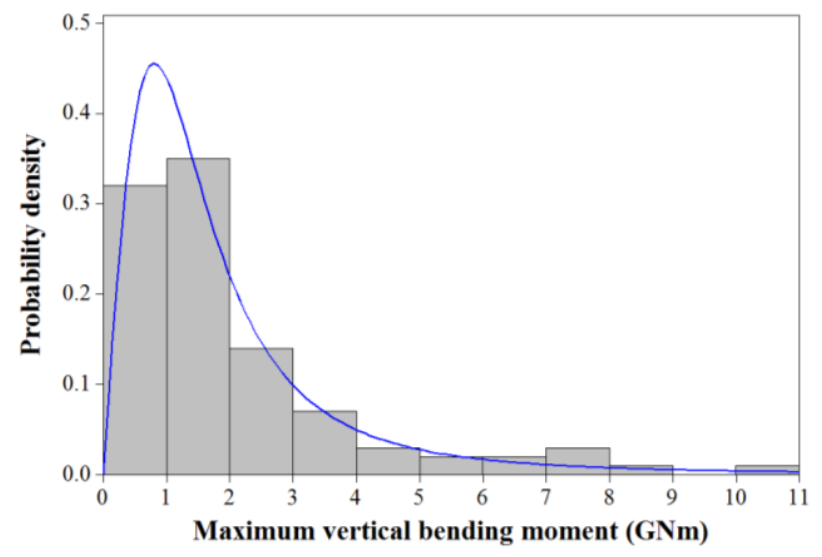

Figure 13. The probability density distribution of the maximum sagging wave-induced vertical bending moment component and its best approximation by the two-parameter log-logistic function, Equation (3), obtained by MAESTRO computations for the example VLCC class tanker in the full load condition. 
Table 4. Maximum sagging wave-induced bending moment components, obtained by MAESTRO computations for the example VLCC class tanker in the full load condition.

\begin{tabular}{|c|c|c|c|c|c|c|c|}
\hline $\begin{array}{l}\text { Scenario } \\
\text { No. }\end{array}$ & $\begin{array}{l}\text { Max. V.B.M. } \\
\text { (GNm) }\end{array}$ & $\begin{array}{l}\text { Scenario } \\
\text { No. }\end{array}$ & $\begin{array}{l}\text { Max. V.B.M. } \\
\text { (GNm) }\end{array}$ & $\begin{array}{l}\text { Scenario } \\
\text { No. }\end{array}$ & $\begin{array}{l}\text { Max. V.B.M. } \\
\text { (GNm) }\end{array}$ & $\begin{array}{l}\text { Scenario } \\
\text { No. }\end{array}$ & $\begin{array}{l}\text { Max. V.B.M. } \\
\text { (GNm) }\end{array}$ \\
\hline 1 & -0.885 & 26 & -1.273 & 51 & -1.146 & 76 & -5.540 \\
\hline 2 & -0.294 & 27 & -0.700 & 52 & -0.513 & 77 & -1.525 \\
\hline 3 & -1.298 & 28 & -0.128 & 53 & -1.467 & 78 & -0.746 \\
\hline 4 & -6.953 & 29 & -1.453 & 54 & -0.331 & 79 & -1.034 \\
\hline 5 & -1.880 & 30 & -0.174 & 55 & -2.228 & 80 & -0.496 \\
\hline 6 & -0.606 & 31 & -1.171 & 56 & -2.860 & 81 & -1.732 \\
\hline 7 & -10.992 & 32 & -2.930 & 57 & -2.536 & 82 & -1.995 \\
\hline 8 & -7.763 & 33 & -0.491 & 58 & -0.729 & 83 & -0.753 \\
\hline 9 & -0.401 & 34 & -3.408 & 59 & -7.422 & 84 & -1.736 \\
\hline 10 & -0.922 & 35 & -1.421 & 60 & -0.806 & 85 & -1.048 \\
\hline 11 & -4.090 & 36 & -1.444 & 61 & -1.859 & 86 & -1.839 \\
\hline 12 & -6.693 & 37 & -0.173 & 62 & -7.374 & 87 & -3.680 \\
\hline 13 & -0.746 & 38 & -1.053 & 63 & -1.874 & 88 & -1.415 \\
\hline 14 & -1.882 & 39 & -3.490 & 64 & -0.432 & 89 & -0.515 \\
\hline 15 & -1.442 & 40 & -2.428 & 65 & -1.017 & 90 & -1.125 \\
\hline 16 & -0.510 & 41 & -0.487 & 66 & -4.185 & 91 & -1.853 \\
\hline 17 & -3.303 & 42 & -1.257 & 67 & -2.194 & 92 & -0.285 \\
\hline 18 & -2.652 & 43 & -1.978 & 68 & -2.521 & 93 & -2.106 \\
\hline 19 & -0.166 & 44 & -2.079 & 69 & -2.219 & 94 & -0.568 \\
\hline 20 & -1.126 & 45 & -3.639 & 70 & -0.274 & 95 & -3.569 \\
\hline 21 & -1.060 & 46 & -5.259 & 71 & -2.902 & 96 & -0.679 \\
\hline 22 & -1.404 & 47 & -1.007 & 72 & -1.719 & 97 & -0.085 \\
\hline 23 & -0.168 & 48 & -0.610 & 73 & -1.346 & 98 & -0.615 \\
\hline 24 & -0.945 & 49 & -2.253 & 74 & -1.782 & 99 & -4.561 \\
\hline 25 & -3.117 & 50 & -2.053 & 75 & -8.685 & 100 & -1.646 \\
\hline
\end{tabular}

Table 4 provides the maximum sagging wave-induced bending moment components in the full load condition. Figure 13 presents the probability density distribution of the maximum wave-induced vertical bending moment component so obtained, together with its best approximation by the twoparameter log-logistic distribution which is expressed as follows:

$$
f(x)=\frac{\beta}{\alpha}\left(\frac{x}{\alpha}\right)^{\beta-1}\left[1+\left(\frac{x}{\alpha}\right)^{\beta}\right]^{-2}
$$

where $\alpha=0.5065$ and $\beta=0.3488$. It is noted that the approximation of the probability density function was undertaken for various different types of functions including normal, two-parameter lognormal, three-parameter log-normal, logistic, two-parameter log-logistic, three-parameter log-logistic, exponential, two-parameter exponential, two-parameter Weibull, three-parameter Weibull, smallest extreme value, largest extreme value, two-parameter Gamma, and three-parameter Gamma functions, 
using the goodness-of-fit test approach. For an applied example associated with ship grounding accidents, Youssef and Paik (2018) may be referred to.

To establish the exceedance probability curve against the maximum wave-induced bending moments, it is required to define the probability of individual wave event scenarios which may be defined as follows:

Probability of wave event $=[$ Probability of significant wave height $\times$ Probability of zero crossing wave period] $\times$ Probability of wave heading angle

In Equation (4), the value of [ ] on the right side can be calculated by taking into account the interacting effects between the significant wave height and the zero crossing wave period using the wave scatter diagram of the North Atlantic sea states, as indicated in Table 2, where either interpolation or extrapolation is applied. On the other hand, the probability of wave heading angle may be estimated by

Probability of wave heading angle $=$ Percentage of wave heading angle occurrence $\times$ Probability of wave heading angle occurrence

Hogben and Lumb (1967) provided the database of wave heading angles that were observed at the North Atlantic Ocean during the 1953-1961 period for 9 years, giving the percentage of wave heading angle occurrence as provided in Table 5 where the wave directions were broken down into 30 degree segments. It is noted that the wave observations were obtained for a number of different ships which took a particular route, so the percentage of wave heading angle occurrence is highest at the heading angle of $225-255 \mathrm{deg}$. This may be due to the fact that the highest probability would be head seas for crossing the Atlantic East to West. In addition, it is assumed that the wind direction changes at sea every $3-6$ hours which may give the probability of wave heading angle occurrence for a period of 25 years as $1 /[25 \times 365 \times 24 / 3]$ where 3 hours are taken. This simplification can be refined as useful wave statistics become available.

Table 5. Percentage of wave heading angle occurrence (Hogben and Lumb 1967)

\begin{tabular}{ccc}
\hline Degree segment & Occurrence & Percentage of occurrence \\
\hline $345-15$ & 1400 & $4.5 \%$ \\
$15-45$ & 1055 & $3.4 \%$ \\
$45-75$ & 1285 & $4.1 \%$ \\
$75-105$ & 1160 & $3.7 \%$ \\
$105-135$ & 1662 & $5.3 \%$ \\
$135-165$ & 2933 & $9.4 \%$ \\
$165-195$ & 3058 & $9.8 \%$ \\
$195-225$ & 4261 & $13.6 \%$ \\
$225-255$ & 6285 & $20.1 \%$ \\
$255-285$ & 3565 & $11.4 \%$ \\
$285-315$ & 2399 & $7.7 \%$ \\
$315-345$ & 2169 & $6.9 \%$ \\
\hline Total & 31232 & $100 \%$ \\
\hline
\end{tabular}

Table 6. Probability of individual wave scenarios associated with the North Atlantic sea states.

\begin{tabular}{ll|ll|ll|ll}
\hline $\begin{array}{l}\text { Scenario } \\
\text { No. }\end{array}$ & $\begin{array}{l}\text { Wave } \\
\text { probability }\end{array}$ & $\begin{array}{l}\text { Scenario } \\
\text { No. }\end{array}$ & $\begin{array}{l}\text { Wave } \\
\text { probability }\end{array}$ & $\begin{array}{l}\text { Scenario } \\
\text { No. }\end{array}$ & $\begin{array}{l}\text { Wave } \\
\text { probability }\end{array}$ & $\begin{array}{l}\text { Scenario } \\
\text { No. }\end{array}$ & $\begin{array}{l}\text { Wave } \\
\text { probability }\end{array}$ \\
\hline 1 & $9.38 \times 10^{-8}$ & 26 & $3.05 \times 10^{-9}$ & 51 & $4.38 \times 10^{-8}$ & 76 & $1.28 \times 10^{-8}$
\end{tabular}




\begin{tabular}{ll|ll|ll|ll}
2 & $2.05 \times 10^{-8}$ & 27 & $5.22 \times 10^{-8}$ & 52 & $3.60 \times 10^{-9}$ & 77 & $3.00 \times 10^{-8}$ \\
3 & $4.37 \times 10^{-13}$ & 28 & $2.79 \times 10^{-11}$ & 53 & $1.94 \times 10^{-8}$ & 78 & $4.67 \times 10^{-8}$ \\
4 & $5.79 \times 10^{-9}$ & 29 & $7.79 \times 10^{-8}$ & 54 & $4.00 \times 10^{-8}$ & 79 & $7.15 \times 10^{-9}$ \\
5 & $9.83 \times 10^{-9}$ & 30 & $1.56 \times 10^{-8}$ & 55 & $4.46 \times 10^{-9}$ & 80 & $9.03 \times 10^{-8}$ \\
6 & $1.73 \times 10^{-10}$ & 31 & $3.26 \times 10^{-8}$ & 56 & $3.02 \times 10^{-8}$ & 81 & $2.56 \times 10^{-8}$ \\
7 & $4.98 \times 10^{-9}$ & 32 & $1.08 \times 10^{-9}$ & 57 & $1.55 \times 10^{-7}$ & 82 & $1.04 \times 10^{-7}$ \\
8 & $2.75 \times 10^{-9}$ & 33 & $1.38 \times 10^{-8}$ & 58 & $1.01 \times 10^{-9}$ & 83 & $1.91 \times 10^{-8}$ \\
9 & $1.12 \times 10^{-9}$ & 34 & $9.55 \times 10^{-9}$ & 59 & $3.63 \times 10^{-8}$ & 84 & $1.31 \times 10^{-8}$ \\
10 & $3.74 \times 10^{-8}$ & 35 & $7.18 \times 10^{-8}$ & 60 & $1.44 \times 10^{-11}$ & 85 & $3.16 \times 10^{-8}$ \\
11 & $9.54 \times 10^{-9}$ & 36 & $1.87 \times 10^{-8}$ & 61 & $2.30 \times 10^{-8}$ & 86 & $2.90 \times 10^{-8}$ \\
12 & $4.22 \times 10^{-9}$ & 37 & $2.13 \times 10^{-8}$ & 62 & $1.36 \times 10^{-8}$ & 87 & $6.03 \times 10^{-8}$ \\
13 & $1.95 \times 10^{-8}$ & 38 & 1.32 & 63 & $6.56 \times 10^{-9}$ & 88 & $1.12 \times 10^{-8}$ \\
14 & $2.86 \times 10^{-8}$ & 39 & $7.87 \times 10^{-9}$ & 64 & $1.67 \times 10^{-9}$ & 89 & $7.59 \times 10^{-8}$ \\
15 & $4.53 \times 10^{-8}$ & 40 & $1.26 \times 10^{-8}$ & 65 & $7.48 \times 10^{-9}$ & 90 & $1.52 \times 10^{-8}$ \\
16 & $4.93 \times 10^{-8}$ & 41 & $2.65 \times 10^{-8}$ & 66 & $1.68 \times 10^{-8}$ & 91 & $1.49 \times 10^{-7}$ \\
17 & $1.05 \times 10^{-7}$ & 42 & $4.48 \times 10^{-8}$ & 67 & $3.87 \times 10^{-8}$ & 92 & $1.31 \times 10^{-8}$ \\
18 & $1.15 \times 10^{-8}$ & 43 & $6.31 \times 10^{-8}$ & 68 & $1.46 \times 10^{-7}$ & 93 & $9.03 \times 10^{-9}$ \\
19 & $5.59 \times 10^{-10}$ & 44 & $3.18 \times 10^{-8}$ & 69 & $2.39 \times 10^{-8}$ & 94 & $6.54 \times 10^{-8}$ \\
20 & $8.05 \times 10^{-8}$ & 45 & $9.30 \times 10^{-8}$ & 70 & $3.91 \times 10^{-8}$ & 95 & $3.27 \times 10^{-8}$ \\
21 & $3.03 \times 10^{-8}$ & 46 & $9.89 \times 10^{-9}$ & 71 & $1.83 \times 10^{-8}$ & 96 & $1.09 \times 10^{-8}$ \\
22 & $1.80 \times 10^{-7}$ & 47 & $7.62 \times 10^{-8}$ & 72 & $7.26 \times 10^{-10}$ & 97 & $2.97 \times 10^{-8}$ \\
23 & $3.89 \times 10^{-8}$ & 48 & $2.68 \times 10^{-8}$ & 73 & $2.04 \times 10^{-8}$ & 98 & $6.44 \times 10^{-8}$ \\
24 & $1.50 \times 10^{-8}$ & 49 & $6.74 \times 10^{-8}$ & 74 & $1.28 \times 10^{-8}$ & 99 & $4.61 \times 10^{-9}$ \\
25 & $6.72 \times 10^{-8}$ & 50 & $8.63 \times 10^{-9}$ & 75 & $2.07 \times 10^{-8}$ & 100 & $1.31 \times 10^{-8}$ \\
\hline & & & & & & &
\end{tabular}

The summary of the wave probability calculations is provided in Table 6. Figure 14 shows the exceedance curve of the maximum wave-induced vertical bending moment for the example VLCC class tanker. The relationship between the probability of exceedance versus any physical parameter is very useful to determine nominal values of safety design and engineering for structural systems, where the physical parameters have been characterized in advance as actions or action effects by refined computations or testing for each of individual scenarios selected. Once the wave probability and the wave-induced loads are calculated for individual scenarios, the exceedance curve can be established by the following four steps.

- Step 1: Establish a table listing the frequency (probability) and target physical parameter for all of the scenarios considered, that can be made by combining Tables 4 and 6 .

- Step 2: Based on the table established in Step 1, rearrange the order of scenarios in such a way that the scenario with the lowest maximum value of the parameter comes first and that with the highest maximum value comes last. Then, calculate the cumulative frequency (probability) in the table, as provided in Table 7.

- Step 3: Based on the table established in Step 2, calculate the exceedance frequency (probability) associated with the maximum value of the parameter. This is equal to the total frequency (probability) minus the cumulative frequency (probability) at the corresponding maximum value of the parameter, as provided in Table 8 .

- Step 4: Determine the design loads or nominal value of structural designs in terms of the maximum parameter at an acceptable level of exceedance probability from the exceedance curve.

Table 7. Rearrangement of the order of the scenarios and their cumulative calculations for Step 2. 


\begin{tabular}{|c|c|c|c|c|c|}
\hline Scenario No. & $\begin{array}{l}\text { Max. V.B.M. } \\
\text { (GNm) }\end{array}$ & $\begin{array}{l}\text { Cumulative } \\
\text { wave } \\
\text { probability }\end{array}$ & Scenario No. & $\begin{array}{l}\text { Max. V.B.M. } \\
\text { (GNm) }\end{array}$ & $\begin{array}{l}\text { Cumulative } \\
\text { wave } \\
\text { probability }\end{array}$ \\
\hline 97 & -0.085 & $2.97 \times 10^{-8}$ & 36 & -1.444 & $1.65 \times 10^{-6}$ \\
\hline 28 & -0.128 & $2.97 \times 10^{-8}$ & 29 & -1.453 & $1.73 \times 10^{-6}$ \\
\hline 19 & -0.166 & $3.02 \times 10^{-8}$ & 53 & -1.467 & $1.75 \times 10^{-6}$ \\
\hline 23 & -0.168 & $6.91 \times 10^{-8}$ & 77 & -1.525 & $1.78 \times 10^{-6}$ \\
\hline 37 & -0.173 & $9.05 \times 10^{-8}$ & 100 & -1.646 & $1.79 \times 10^{-6}$ \\
\hline 30 & -0.174 & $1.06 \times 10^{-7}$ & 72 & -1.719 & $1.79 \times 10^{-6}$ \\
\hline 70 & -0.274 & $1.45 \times 10^{-7}$ & 81 & -1.732 & $1.82 \times 10^{-6}$ \\
\hline 92 & -0.285 & $1.58 \times 10^{-7}$ & 84 & -1.736 & $1.83 \times 10^{-6}$ \\
\hline 2 & -0.294 & $1.79 \times 10^{-7}$ & 74 & -1.782 & $1.85 \times 10^{-6}$ \\
\hline 54 & -0.331 & $2.19 \times 10^{-7}$ & 86 & -1.839 & $1.87 \times 10^{-6}$ \\
\hline 9 & -0.401 & $2.20 \times 10^{-7}$ & 91 & -1.853 & $2.02 \times 10^{-6}$ \\
\hline 64 & -0.432 & $2.22 \times 10^{-7}$ & 61 & -1.859 & $2.05 \times 10^{-6}$ \\
\hline 41 & -0.487 & $2.48 \times 10^{-7}$ & 63 & -1.874 & $2.05 \times 10^{-6}$ \\
\hline 33 & -0.491 & $2.62 \times 10^{-7}$ & 5 & -1.880 & $2.06 \times 10^{-6}$ \\
\hline 80 & -0.496 & $3.52 \times 10^{-7}$ & 14 & -1.882 & $2.09 \times 10^{-6}$ \\
\hline 16 & -0.510 & $4.02 \times 10^{-7}$ & 43 & -1.978 & $2.15 \times 10^{-6}$ \\
\hline 52 & -0.513 & $4.05 \times 10^{-7}$ & 82 & -1.995 & $2.26 \times 10^{-6}$ \\
\hline 89 & -0.515 & $4.81 \times 10^{-7}$ & 50 & -2.053 & $2.27 \times 10^{-6}$ \\
\hline 94 & -0.568 & $5.47 \times 10^{-7}$ & 44 & -2.079 & $2.30 \times 10^{-6}$ \\
\hline 6 & -0.606 & $5.47 \times 10^{-7}$ & 93 & -2.106 & $2.31 \times 10^{-6}$ \\
\hline 48 & -0.610 & $5.73 \times 10^{-7}$ & 67 & -2.194 & $2.35 \times 10^{-6}$ \\
\hline 98 & -0.615 & $6.38 \times 10^{-7}$ & 69 & -2.219 & $2.37 \times 10^{-6}$ \\
\hline 96 & -0.679 & $6.49 \times 10^{-7}$ & 55 & -2.228 & $2.38 \times 10^{-6}$ \\
\hline 27 & -0.700 & $7.01 \times 10^{-7}$ & 49 & -2.253 & $2.44 \times 10^{-6}$ \\
\hline 58 & -0.729 & $7.02 \times 10^{-7}$ & 40 & -2.428 & $2.46 \times 10^{-6}$ \\
\hline 13 & -0.746 & $7.21 \times 10^{-7}$ & 68 & -2.521 & $2.60 \times 10^{-6}$ \\
\hline 78 & -0.746 & $7.68 \times 10^{-7}$ & 57 & -2.536 & $2.76 \times 10^{-6}$ \\
\hline 83 & -0.753 & $7.87 \times 10^{-7}$ & 18 & -2.652 & $2.77 \times 10^{-6}$ \\
\hline 60 & -0.806 & $7.87 \times 10^{-7}$ & 56 & -2.860 & $2.80 \times 10^{-6}$ \\
\hline 1 & -0.885 & $8.81 \times 10^{-7}$ & 71 & -2.902 & $2.82 \times 10^{-6}$ \\
\hline 10 & -0.922 & $9.18 \times 10^{-7}$ & 32 & -2.930 & $2.82 \times 10^{-6}$ \\
\hline 24 & -0.945 & $9.33 \times 10^{-7}$ & 25 & -3.117 & $2.89 \times 10^{-6}$ \\
\hline 47 & -1.007 & $1.01 \times 10^{-6}$ & 17 & -3.303 & $2.99 \times 10^{-6}$ \\
\hline 65 & -1.017 & $1.02 \times 10^{-6}$ & 34 & -3.408 & $3.00 \times 10^{-6}$ \\
\hline 79 & -1.034 & $1.02 \times 10^{-6}$ & 39 & -3.490 & $3.01 \times 10^{-6}$ \\
\hline 85 & -1.048 & $1.06 \times 10^{-6}$ & 95 & -3.569 & $3.04 \times 10^{-6}$ \\
\hline 38 & -1.053 & $1.06 \times 10^{-6}$ & 45 & -3.639 & $3.13 \times 10^{-6}$ \\
\hline 21 & -1.060 & $1.09 \times 10^{-6}$ & 87 & -3.680 & $3.19 \times 10^{-6}$ \\
\hline 90 & -1.125 & $1.10 \times 10^{-6}$ & 11 & -4.090 & $3.20 \times 10^{-6}$ \\
\hline 20 & -1.126 & $1.18 \times 10^{-6}$ & 66 & -4.185 & $3.22 \times 10^{-6}$ \\
\hline 51 & -1.146 & $1.23 \times 10^{-6}$ & 99 & -4.561 & $3.22 \times 10^{-6}$ \\
\hline
\end{tabular}




\begin{tabular}{lll|lll}
31 & -1.171 & $1.26 \times 10^{-6}$ & 46 & -5.259 & $3.23 \times 10^{-6}$ \\
42 & -1.257 & $1.30 \times 10^{-6}$ & 76 & -5.540 & $3.25 \times 10^{-6}$ \\
26 & -1.273 & $1.31 \times 10^{-6}$ & 12 & -6.693 & $3.25 \times 10^{-6}$ \\
3 & -1.298 & $1.31 \times 10^{-6}$ & 4 & -6.953 & $3.26 \times 10^{-6}$ \\
73 & -1.346 & $1.33 \times 10^{-6}$ & 62 & -7.374 & $3.27 \times 10^{-6}$ \\
22 & -1.404 & $1.51 \times 10^{-6}$ & 59 & -7.422 & $3.31 \times 10^{-6}$ \\
88 & -1.415 & $1.52 \times 10^{-6}$ & 8 & -7.763 & $3.31 \times 10^{-6}$ \\
35 & -1.421 & $1.59 \times 10^{-6}$ & 75 & -8.685 & $3.33 \times 10^{-6}$ \\
15 & -1.442 & $1.63 \times 10^{-6}$ & 7 & -10.992 & $3.34 \times 10^{-6}$ \\
\hline
\end{tabular}

Table 8. Exceedance probability associated with the maximum value of the parameter for Step 3.

\begin{tabular}{|c|c|c|c|c|c|}
\hline Scenario No. & $\begin{array}{l}\text { Max. V.B.M. } \\
(\mathrm{GNm})\end{array}$ & $\begin{array}{l}\text { Exceedance } \\
\text { wave } \\
\text { probability }\end{array}$ & Scenario No. & $\begin{array}{l}\text { Max. V.B.M. } \\
(\text { GNm) }\end{array}$ & $\begin{array}{l}\text { Exceedance } \\
\text { wave } \\
\text { probability }\end{array}$ \\
\hline 97 & -0.085 & $3.31 \times 10^{-6}$ & 36 & -1.444 & $1.68 \times 10^{-6}$ \\
\hline 28 & -0.128 & $3.31 \times 10^{-6}$ & 29 & -1.453 & $1.61 \times 10^{-6}$ \\
\hline 19 & -0.166 & $3.31 \times 10^{-6}$ & 53 & -1.467 & $1.59 \times 10^{-6}$ \\
\hline 23 & -0.168 & $3.27 \times 10^{-6}$ & 77 & -1.525 & $1.56 \times 10^{-6}$ \\
\hline 37 & -0.173 & $3.25 \times 10^{-6}$ & 100 & -1.646 & $1.54 \times 10^{-6}$ \\
\hline 30 & -0.174 & $3.23 \times 10^{-6}$ & 72 & -1.719 & $1.54 \times 10^{-6}$ \\
\hline 70 & -0.274 & $3.19 \times 10^{-6}$ & 81 & -1.732 & $1.52 \times 10^{-6}$ \\
\hline 92 & -0.285 & $3.18 \times 10^{-6}$ & 84 & -1.736 & $1.50 \times 10^{-6}$ \\
\hline 2 & -0.294 & $3.16 \times 10^{-6}$ & 74 & -1.782 & $1.49 \times 10^{-6}$ \\
\hline 54 & -0.331 & $3.12 \times 10^{-6}$ & 86 & -1.839 & $1.46 \times 10^{-6}$ \\
\hline 9 & -0.401 & $3.12 \times 10^{-6}$ & 91 & -1.853 & $1.31 \times 10^{-6}$ \\
\hline 64 & -0.432 & $3.11 \times 10^{-6}$ & 61 & -1.859 & $1.29 \times 10^{-6}$ \\
\hline 41 & -0.487 & $3.09 \times 10^{-6}$ & 63 & -1.874 & $1.28 \times 10^{-6}$ \\
\hline 33 & -0.491 & $3.07 \times 10^{-6}$ & 5 & -1.880 & $1.27 \times 10^{-6}$ \\
\hline 80 & -0.496 & $2.98 \times 10^{-6}$ & 14 & -1.882 & $1.24 \times 10^{-6}$ \\
\hline 16 & -0.510 & $2.93 \times 10^{-6}$ & 43 & -1.978 & $1.18 \times 10^{-6}$ \\
\hline 52 & -0.513 & $2.93 \times 10^{-6}$ & 82 & -1.995 & $1.08 \times 10^{-6}$ \\
\hline 89 & -0.515 & $2.85 \times 10^{-6}$ & 50 & -2.053 & $1.07 \times 10^{-6}$ \\
\hline 94 & -0.568 & $2.79 \times 10^{-6}$ & 44 & -2.079 & $1.04 \times 10^{-6}$ \\
\hline 6 & -0.606 & $2.79 \times 10^{-6}$ & 93 & -2.106 & $1.03 \times 10^{-6}$ \\
\hline 48 & -0.610 & $2.76 \times 10^{-6}$ & 67 & -2.194 & $9.89 \times 10^{-7}$ \\
\hline 98 & -0.615 & $2.70 \times 10^{-6}$ & 69 & -2.219 & $9.65 \times 10^{-7}$ \\
\hline 96 & -0.679 & $2.69 \times 10^{-6}$ & 55 & -2.228 & $9.60 \times 10^{-7}$ \\
\hline 27 & -0.700 & $2.64 \times 10^{-6}$ & 49 & -2.253 & $8.93 \times 10^{-7}$ \\
\hline 58 & -0.729 & $2.63 \times 10^{-6}$ & 40 & -2.428 & $8.80 \times 10^{-7}$ \\
\hline 13 & -0.746 & $2.61 \times 10^{-6}$ & 68 & -2.521 & $7.34 \times 10^{-7}$ \\
\hline 78 & -0.746 & $2.57 \times 10^{-6}$ & 57 & -2.536 & $5.79 \times 10^{-7}$ \\
\hline 83 & -0.753 & $2.55 \times 10^{-6}$ & 18 & -2.652 & $5.67 \times 10^{-7}$ \\
\hline 60 & -0.806 & $2.55 \times 10^{-6}$ & 56 & -2.860 & $5.37 \times 10^{-7}$ \\
\hline
\end{tabular}




\begin{tabular}{lll|lll}
1 & -0.885 & $2.45 \times 10^{-6}$ & 71 & -2.902 & $5.19 \times 10^{-7}$ \\
10 & -0.922 & $2.42 \times 10^{-6}$ & 32 & -2.930 & $5.18 \times 10^{-7}$ \\
24 & -0.945 & $2.40 \times 10^{-6}$ & 25 & -3.117 & $4.50 \times 10^{-7}$ \\
47 & -1.007 & $2.33 \times 10^{-6}$ & 17 & -3.303 & $3.45 \times 10^{-7}$ \\
65 & -1.017 & $2.32 \times 10^{-6}$ & 34 & -3.408 & $3.36 \times 10^{-7}$ \\
79 & -1.034 & $2.31 \times 10^{-6}$ & 39 & -3.490 & $3.28 \times 10^{-7}$ \\
85 & -1.048 & $2.28 \times 10^{-6}$ & 95 & -3.569 & $2.95 \times 10^{-7}$ \\
38 & -1.053 & $2.28 \times 10^{-6}$ & 45 & -3.639 & $2.02 \times 10^{-7}$ \\
21 & -1.060 & $2.25 \times 10^{-6}$ & 87 & -3.680 & $1.42 \times 10^{-7}$ \\
90 & -1.125 & $2.23 \times 10^{-6}$ & 11 & -4.090 & $1.33 \times 10^{-7}$ \\
20 & -1.126 & $2.15 \times 10^{-6}$ & 66 & -4.185 & $1.16 \times 10^{-7}$ \\
51 & -1.146 & $2.11 \times 10^{-6}$ & 99 & -4.561 & $1.11 \times 10^{-7}$ \\
31 & -1.171 & $2.08 \times 10^{-6}$ & 46 & -5.259 & $1.01 \times 10^{-7}$ \\
42 & -1.257 & $2.03 \times 10^{-6}$ & 76 & -5.540 & $8.83 \times 10^{-8}$ \\
26 & -1.273 & $2.03 \times 10^{-6}$ & 12 & -6.693 & $8.41 \times 10^{-8}$ \\
3 & -1.298 & $2.03 \times 10^{-6}$ & 4 & -6.953 & $7.83 \times 10^{-8}$ \\
73 & -1.346 & $2.01 \times 10^{-6}$ & 62 & -7.374 & $6.47 \times 10^{-8}$ \\
22 & -1.404 & $1.83 \times 10^{-6}$ & 59 & -7.422 & $2.84 \times 10^{-8}$ \\
88 & -1.415 & $1.82 \times 10^{-6}$ & 8 & -7.763 & $2.56 \times 10^{-8}$ \\
35 & -1.421 & $1.75 \times 10^{-6}$ & 75 & -8.685 & $4.98 \times 10^{-9}$ \\
15 & -1.442 & $1.70 \times 10^{-6}$ & 7 & -10.992 & 0.00 \\
\hline
\end{tabular}

In contrast, IACS (2010) has suggested the following equation for estimating the design values of the wave induced vertical bending moments for merchant cargo ships including oil tankers.

$$
M_{w}= \begin{cases}+0.19 C_{1} C_{2} L^{2} B C_{b} & \text { for kNm for hogging } \\ -0.11 C_{1} C_{2} L^{2} B\left(C_{b}+0.7\right) & \text { for kNm for sagging }\end{cases}
$$

where,

$$
C_{1}=\left\{\begin{array}{lc}
0.0792 L & \text { for } L<90 \\
10.75-[(300-L) / 100]^{1.5} & \text { for } 90 \leq L \leq 300 \\
10.75 & \text { for } 300<L \leq 350 \\
10.75-[(L-350) / 150]^{1.5} & \text { for } 350<L \leq 500
\end{array}\right.
$$

For the example VLCC class tanker, $C_{1}=10.75, C_{2}=1$ amidships, scantling length $L=$ $308.363 \mathrm{~m}$ which may be taken as $0.97 L_{L W L}, B=60 \mathrm{~m}, D=30 \mathrm{~m}, C_{b}=0.81$, and thus the wave-induced vertical bending moments $M_{w}$ are given as follows:

$$
M_{w}=\left\{\begin{array}{l}
+9.438 \mathrm{GNm} \text { for hogging } \\
-10.186 \mathrm{GNm} \text { for sagging }
\end{array}\right.
$$

It is noted that the background of the IACS formula is totally different from the method described in this paper, but rather it is based on past experiences of successful or damaged ships in design and operation, as well as theoretical or experimental findings associated with the so-called most unfavorable wave events during the design life time of the ships. 
Regardless of such differences, the IACS formula calculations may be considered to be useful as a reference of the ALARP (as low as reasonably practicable) acceptance criteria. It is interesting to note that the expected number $N$ of wave peaks during the entire life time (25 years) of a ship may be estimated as $\mathrm{N}=25 \times 365 \times 24 \times 60 \times 60 / 10=78,840,000$ or $\mathrm{N}=25 \times 365 \times 24 \times 60 \times 60 / 6=$ $131,400,000$ if a wave peak occurs every $6-10 \mathrm{~s}$ (Paik 2018). The occurrence probability of the maximum wave peaks is then in the range of $7.61 \times 10^{-9}-1.27 \times 10^{-8}$.

Figure 14 compares the design values of the maximum sagging wave-induced bending moments between the proposed method and the IACS (2010) formula estimation of Equation (6) for the example VLCC class tanker. The present method gives $-8.44 \mathrm{GNm}$ for the design value in association with the acceptance criteria of exceedance probability in the range of $7.61 \times 10^{-9}-1.27 \times 10^{-8}$, which is $17.2 \%$ lower than the IACS formula. The difference between the two methods may be due to the nonlinear effects associated with irregular sea states, among other factors.

The total vertical bending moment can be obtained as sum of still-water and wave-induced bending moment components, see Table 15 later. While the still-water bending moment component is recommended to be calculated directly from the loading conditions, the IACS guideline is also available to predict the design value of the still-water bending moment component. The total vertical bending moment obtained by the proposed method with the direction calculation of the still-water bending moment is smaller than the IACS rule predictions with the direction calculation of the stillwater bending moment by $10.26 \%$ and it is greater than the proposed method with the IACS rule value of the still-water bending moment component by $2.13 \%$, indicating that both the IACS rule predictions and the proposed method computations are in good agreement in the total vertical bending moments.

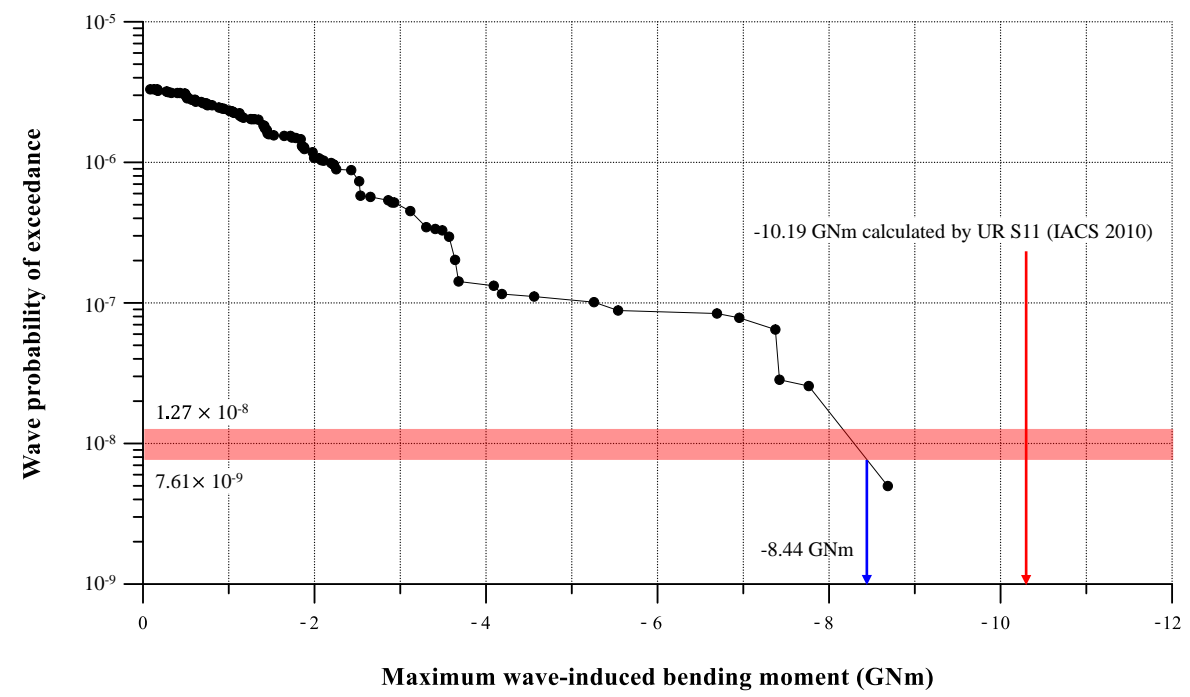

Figure 14. Wave probability of exceedance associated with the maximum sagging wave-induced bending moments for the example VLCC class tanker in the full load condition.

\section{Application to an as-built 9,300 TEU Containership}

The same method described in Section 2 is now applied to determine the wave-induced design loads of an as-built 9,300 TEU containership. Table 9 provides the principal dimensions of the example containership. Figure 15 shows the three-dimensional finite element analysis model of the entire ship.

Table 9. Principal dimensions of the example 9,300 TEU containership.

\begin{tabular}{ll}
\hline Parameter & Dimension \\
\hline Length between perpendiculars $\left(L_{B P}\right)$ & $286.0 \mathrm{~m}$ \\
Length on summer load waterline $\left(L_{L W L}\right)$ & $291.6 \mathrm{~m}$ \\
Breadth $(B)$ & $48.2 \mathrm{~m}$ \\
Depth $(D)$ & $25.0 \mathrm{~m}$
\end{tabular}




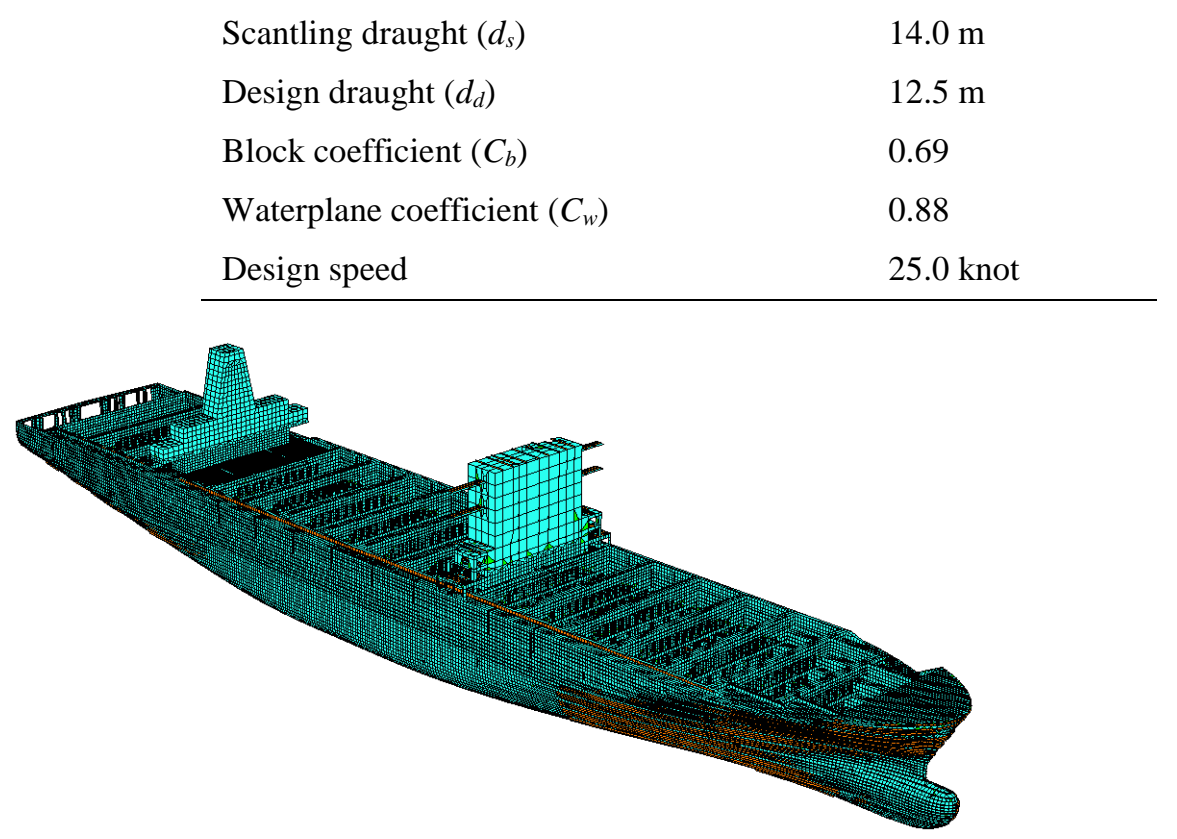

(a) Overall view

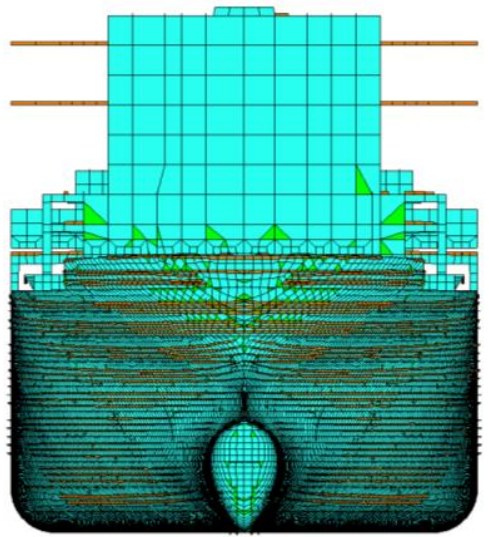

(b) Body plan view

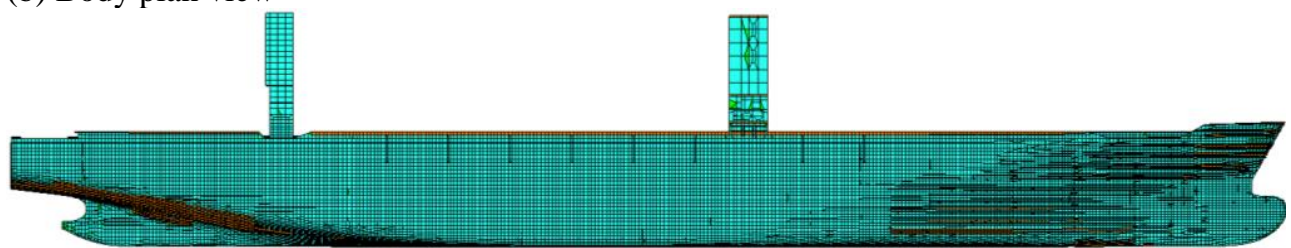

(c) Profile view

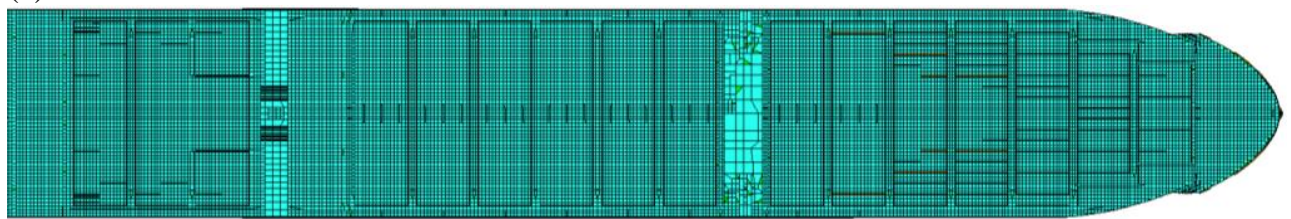

(d) Plan view

Figure 15. Three-dimensional FEA model of the example 9,300 TEU containership.

Until June of 2016, Equation (6), which is the IACS formula used for estimating the wave-induced vertical bending moments $M_{w}$ of bulkers and oil tankers, has also been applied to containerships (IACS 2010). However, new formulas (IACS 2015) have been introduced to take into account the different characteristics of containerships' hull forms, which are much more slender than bulkers or tankers, and has been applied since $1^{\text {st }}$ July 2016 : 


$$
M_{w}= \begin{cases}+1.5 f_{R} L^{3} C C_{w}\left(\frac{B}{L}\right)^{0.8} f_{N L-H o g} & \mathrm{kNm} \text { for hogging } \\ -1.5 f_{R} L^{3} C C_{w}\left(\frac{B}{L}\right)^{0.8} f_{N L-S a g} & \mathrm{kNm} \text { for sagging }\end{cases}
$$

where $f_{R}$ is the factor related to the operational profile, $L$ is the scantling length in $\mathrm{m}$ which may be taken as $L=0.97 L_{L W L}, C_{w}$ is the waterplane coefficient at the scantling draught, $B$ is the moulded breadth in $\mathrm{m}, C_{b}$ is the block coefficient, $d_{s}$ is the scantling draught in $\mathrm{m}, C$ is the wave parameter which can be taken as follows:

$C=\left\{\begin{array}{l}1-1.5\left(1-\sqrt{\frac{L}{L_{r e f}}}\right)^{2.2} \quad \text { for } L \leq L_{r e f} \\ 1-0.45\left(\sqrt{\frac{L}{L_{r e f}}}-1\right)^{1.7} \text { for } L>L_{r e f}\end{array}\right.$,

$L_{r e f}$ is the reference length in m, which can be taken as follows:

$L_{r e f}=\left\{\begin{array}{l}315 C_{w}^{-1.3} \text { for wave induced vertical bending moments } \\ 330 C_{w}^{-1.3} \text { for wave induced vertical shear forces }\end{array}\right.$,

$f_{N L-H o g}$ is the nonlinear correction factor for hogging which can be taken as follows:

$f_{N L-H o g}=0.3 \frac{C_{b}}{C_{w}} \sqrt{d_{s}}$, not to be taken greater than 1.1,

$f_{N L-S a g}$ is the nonlinear correction factor for sagging which can be taken as follows:

$f_{N L-S a g}=4.5 \frac{1+0.2 f_{\text {bow }}}{C_{w} \sqrt{C_{b}} L^{0.3}}$, not to be taken less than 1.0,

$f_{\text {bow }}$ is the coefficient of bow flare shape which can be taken as follows:

$f_{\text {bow }}=\frac{A_{D K}-A_{W L}}{0.2 L z_{f}}$,

$A_{D K}$ is the projected area in the horizontal plane of the uppermost deck in $\mathrm{m}^{2}$, extending from $0.8 \mathrm{~L}$ forward,

$A_{W L}$ is the waterplane area in $\mathrm{m}^{2}$, extending from $0.8 L$ forward,

$z_{f}$ is the vertical distance in $\mathrm{m}$, from the waterline to the uppermost deck.

Containerships are predominantly in hogging at the full load condition. When the IACS (2010) formula of Equation (6) is applied, therefore, the hogging wave-induced design vertical bending moment is given as follows:

$$
M_{w}=+5.45 \mathrm{GNm}
$$

On the other hand, the IACS (2015) formula of Equation (8) gives a slightly smaller value than the IACS (2010) formula of Equation (6) in hogging condition as follows:

$$
M_{w}=+5.35 \mathrm{GNm}
$$

where $L=282.852 \mathrm{~m}, B=48.2 \mathrm{~m}, d_{s}=14.0 \mathrm{~m}, C_{b}=0.69, C_{w}=0.88, f_{R}=0.85$, 


$$
\begin{aligned}
& L_{r e f}=315 C_{w}^{-1.3}=372.349 \mathrm{~m}, C=1.0-1.5\left(1-\sqrt{\frac{L}{L_{r e f}}}\right)^{2.2}=0.98359, f_{N L-H o g}=0.3 \frac{C_{b}}{C_{w}} \sqrt{d_{s}}=0.883, \\
& f_{N L-S a g}=4.5 \frac{1.0+0.2 f_{\text {bow }}}{C_{w} \sqrt{C_{b}} L^{0.3}}=1.632, f_{\text {bow }}=\frac{A_{D K}-A_{W L}}{0.2 L z_{f}}=\frac{2514.542-1137.012}{0.2 \times 282.0 \times 852.0 \times 11.0}=2.2137 .
\end{aligned}
$$

To predict the wave-induced structural loads of the example 9,300 TEU containership using the same procedure described in Figure 3, the exactly same set of the wave event scenarios as of the VLCC class tanker indicated in Table 3 can be applied. Figure 16 shows the wave elevations of selected scenarios for the 9,300 TEU containership. Table 10 indicates the maximum hogging wave-induced bending moment components for individual wave event scenarios. Figure 17 shows the distributions of the total and wave-induced vertical bending moments of the example 9,300 TEU containership for selected wave scenarios along the example ship's length. Figure 18 shows the probability density distribution of the maximum hogging wave-induced bending moments and its approximation using two-parameter Weibull distribution which is give as follows:

$$
f(x)=\frac{\beta}{\alpha}\left(\frac{x}{\alpha}\right)^{\beta-1} \exp \left[-\left(\frac{x}{\alpha}\right)^{\beta}\right]
$$

where $\alpha=1.326$ and $\beta=1.105$.

Figure 19 shows the wave probability of exceedance associated with the maximum hogging waveinduced bending moments for the example 9,300 TEU containership. The present method gives 3.99 GNm for the design value in association with the acceptance criteria of exceedance probability in the range of $7.61 \times 10^{-9}-1.27 \times 10^{-8}$, which is $25.4 \%$ lower than the IACS (2015) formula estimation of Equation (8). Again, it is considered that the difference between the two methods may be due to the nonlinear effects associated with irregular sea states and operating speed, etc.

The total vertical bending moment obtained by the proposed method with the direction calculation of the still-water bending moment is smaller than the IACS rule predictions with the direction calculation of the still-water bending moment by $10.95 \%$ and it is greater than the proposed method with the IACS rule value of the still-water bending moment component by $13.27 \%$, indicating that both the IACS rule predictions and the proposed method computations are still in reasonably good agreement in the total vertical bending moments.

Table 10. Maximum hogging wave-induced bending moment components of the example 9,300 TEU containership for individual wave event scenarios in the full load condition.

\begin{tabular}{ll|ll|ll|ll}
\hline $\begin{array}{l}\text { Scenario } \\
\text { No. }\end{array}$ & $\begin{array}{l}\text { Max. V.B.M. } \\
(\mathrm{GNm})\end{array}$ & $\begin{array}{l}\text { Scenario } \\
\text { No. }\end{array}$ & $\begin{array}{l}\text { Max. V.B.M. } \\
(\mathrm{GNm})\end{array}$ & $\begin{array}{l}\text { Scenario } \\
\text { No. }\end{array}$ & $\begin{array}{l}\text { Max. V.B.M. } \\
(\mathrm{GNm})\end{array}$ & $\begin{array}{l}\text { Scenario } \\
\text { No. }\end{array}$ & $\begin{array}{l}\text { Max. V.B.M. } \\
\text { (GNm) }\end{array}$ \\
\hline 1 & 0.606 & 26 & 0.770 & 51 & 0.677 & 76 & 3.259 \\
2 & 0.380 & 27 & 0.808 & 52 & 0.748 & 77 & 1.235 \\
3 & 0.001 & 28 & 0.164 & 53 & 0.799 & 78 & 1.010 \\
4 & 4.356 & 29 & 1.204 & 54 & 0.186 & 79 & 0.952 \\
5 & 0.791 & 30 & 0.097 & 55 & 1.463 & 80 & 0.476 \\
6 & 0.289 & 31 & 1.013 & 56 & 1.737 & 81 & 1.030 \\
7 & 0.002 & 32 & 1.399 & 57 & 0.811 & 82 & 1.001 \\
8 & 2.250 & 33 & 0.550 & 58 & 0.698 & 83 & 0.662 \\
9 & 0.194 & 34 & 1.703 & 59 & 0.069 & 84 & 1.378 \\
10 & 1.113 & 35 & 0.792 & 60 & 0.439 & 85 & 0.824 \\
11 & 3.972 & 36 & 0.741 & 61 & 1.788 & 86 & 0.322 \\
12 & 3.960 & 37 & 0.247 & 62 & 0.074 & 87 & 1.186 \\
13 & 0.389 & 38 & 0.288 & 63 & 1.319 & 88 & 1.425
\end{tabular}




\begin{tabular}{ll|ll|ll|ll}
14 & 1.046 & 39 & 2.057 & 64 & 0.004 & 89 & 0.410 \\
15 & 1.471 & 40 & 1.391 & 65 & 0.829 & 90 & 0.666 \\
16 & 0.595 & 41 & 0.286 & 66 & 1.121 & 91 & 0.835 \\
17 & 2.017 & 42 & 0.473 & 67 & 0.886 & 92 & 0.336 \\
18 & 1.050 & 43 & 0.069 & 68 & 0.863 & 93 & 2.274 \\
19 & 0.130 & 44 & 2.298 & 69 & 0.665 & 94 & 0.337 \\
20 & 0.628 & 45 & 0.534 & 70 & 0.241 & 95 & 0.088 \\
21 & 1.341 & 46 & 2.922 & 71 & 1.269 & 96 & 0.511 \\
22 & 1.367 & 47 & 0.780 & 72 & 0.670 & 97 & 0.100 \\
23 & 0.157 & 48 & 0.582 & 73 & 1.082 & 98 & 0.170 \\
24 & 0.559 & 49 & 1.974 & 74 & 1.777 & 99 & 2.271 \\
25 & 1.066 & 50 & 2.218 & 75 & 0.205 & 100 & 0.608 \\
\hline
\end{tabular}

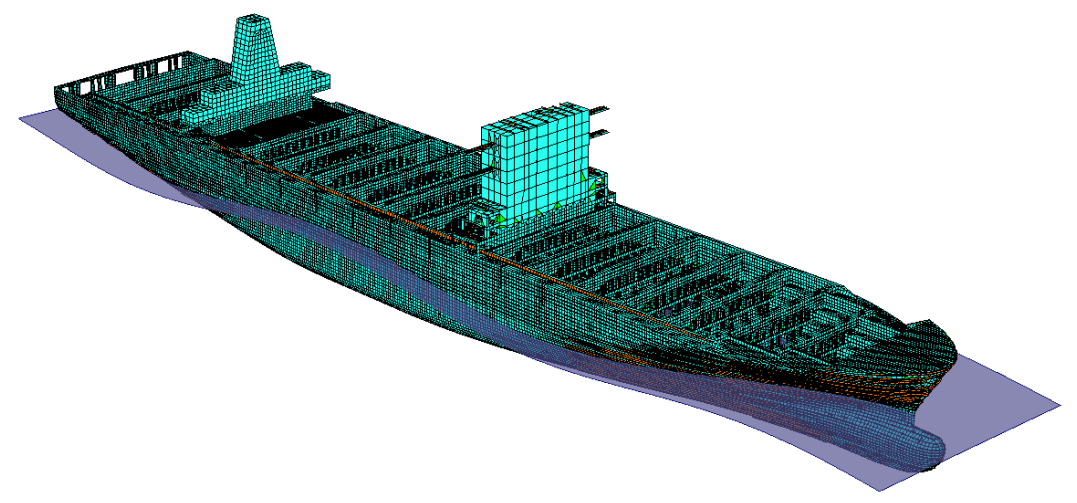

(a) Scenario 50 at wave direction of 9 deg. and phase angle of 270 deg.

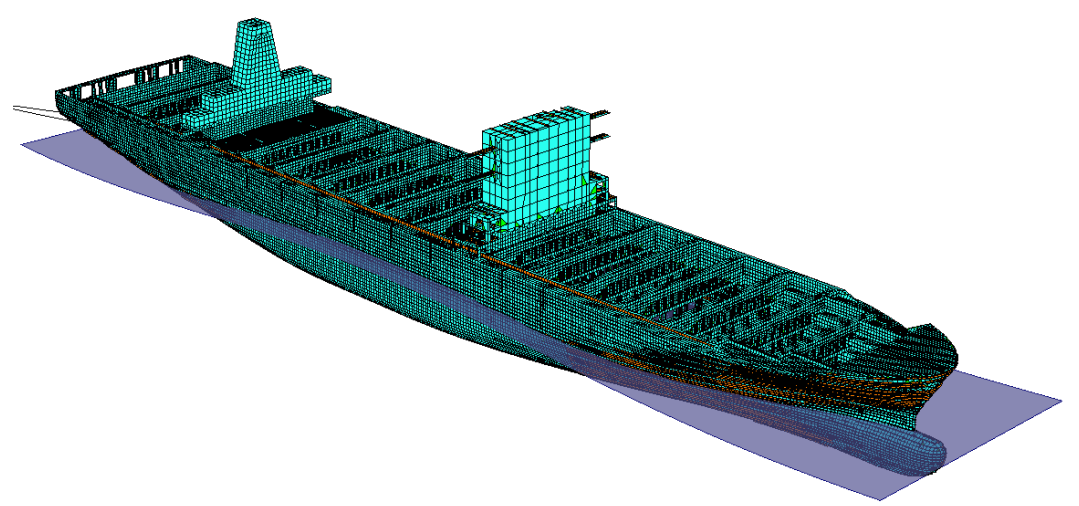

(b) Scenario 76 wave direction of $203.4 \mathrm{deg}$. and phase angle of $180 \mathrm{deg}$.

Figure 16. Wave elevations of selected scenarios for the example 9,300 TEU containership. 


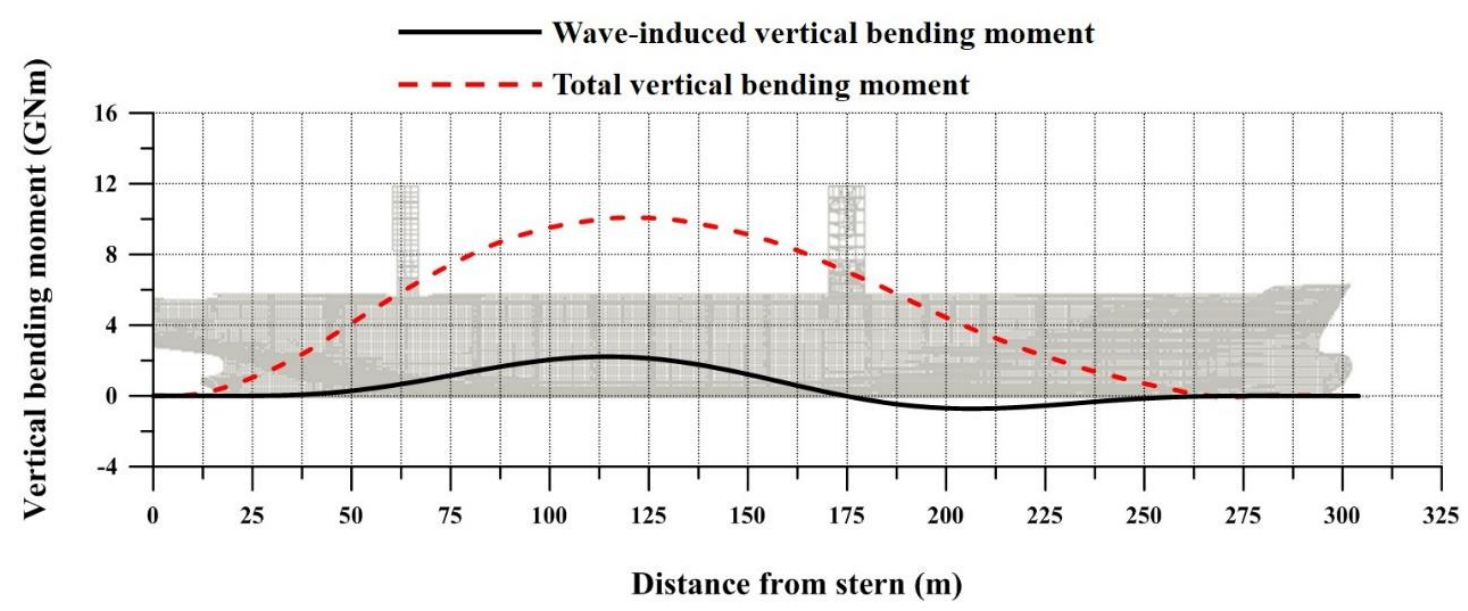

(a) Scenario 50 at wave direction of $9 \mathrm{deg}$. and phase angle of $270 \mathrm{deg}$.

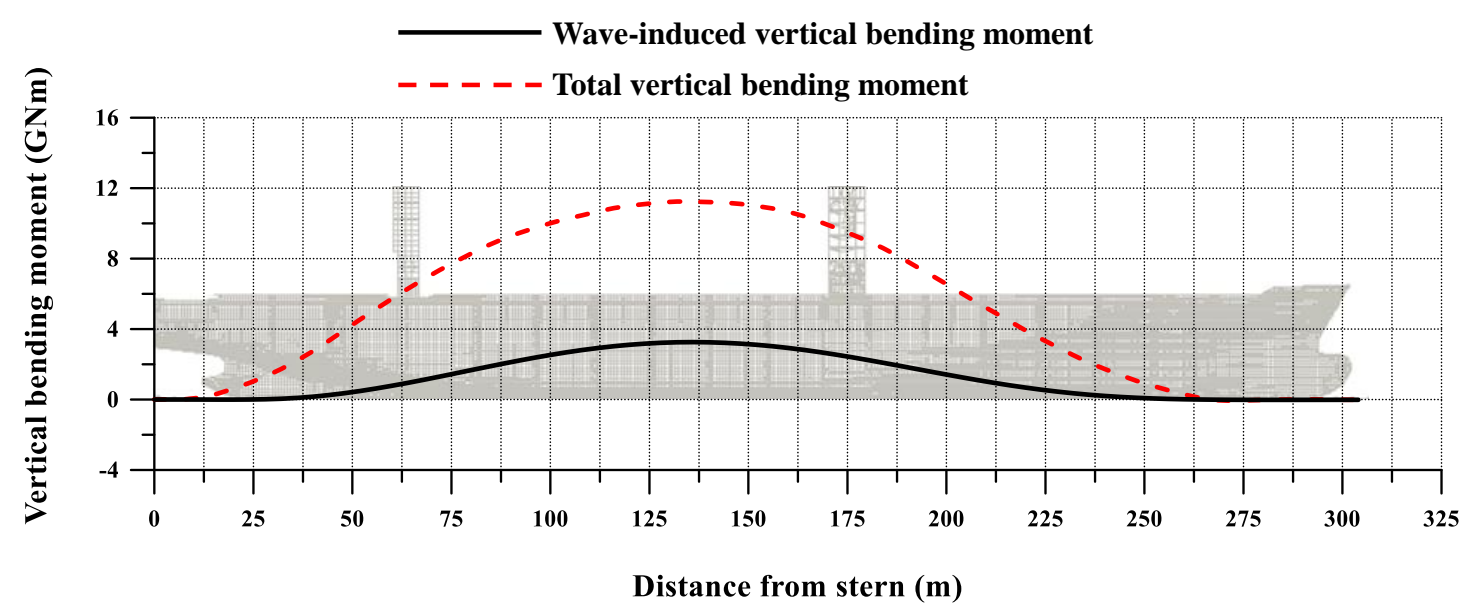

(b) Scenario 76 wave direction of $203.4 \mathrm{deg}$. and phase angle of $180 \mathrm{deg}$.

Figure 17. Distributions of total and wave-induced vertical bending moments of the example 9,300 TEU containership for selected wave scenarios in the full load condition.

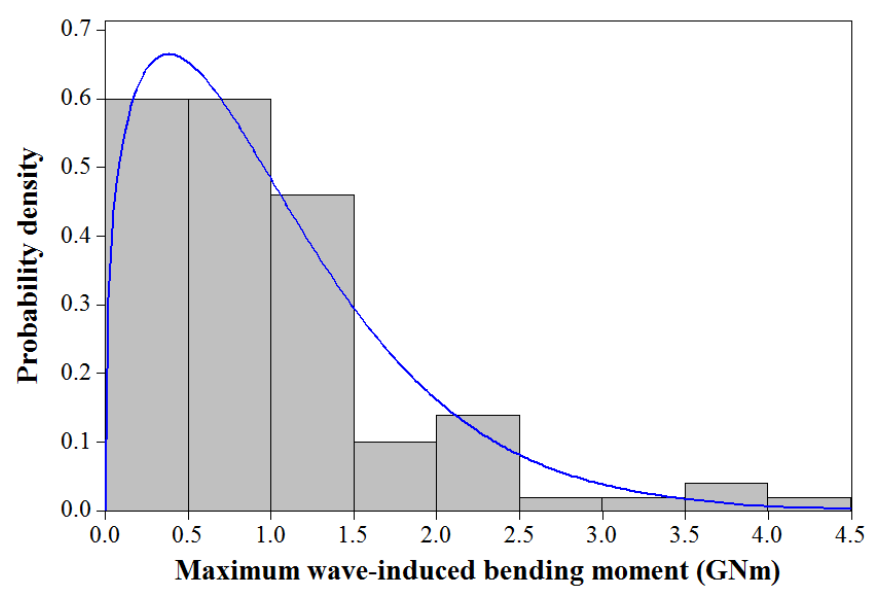

Figure 18. Distribution of the maximum hogging wave-induced bending moments and its best approximation by the two-parameter Weibull function, Equation (11), obtained by MAESTRO computations for the example 9,300 TEU containership in the full load condition. 


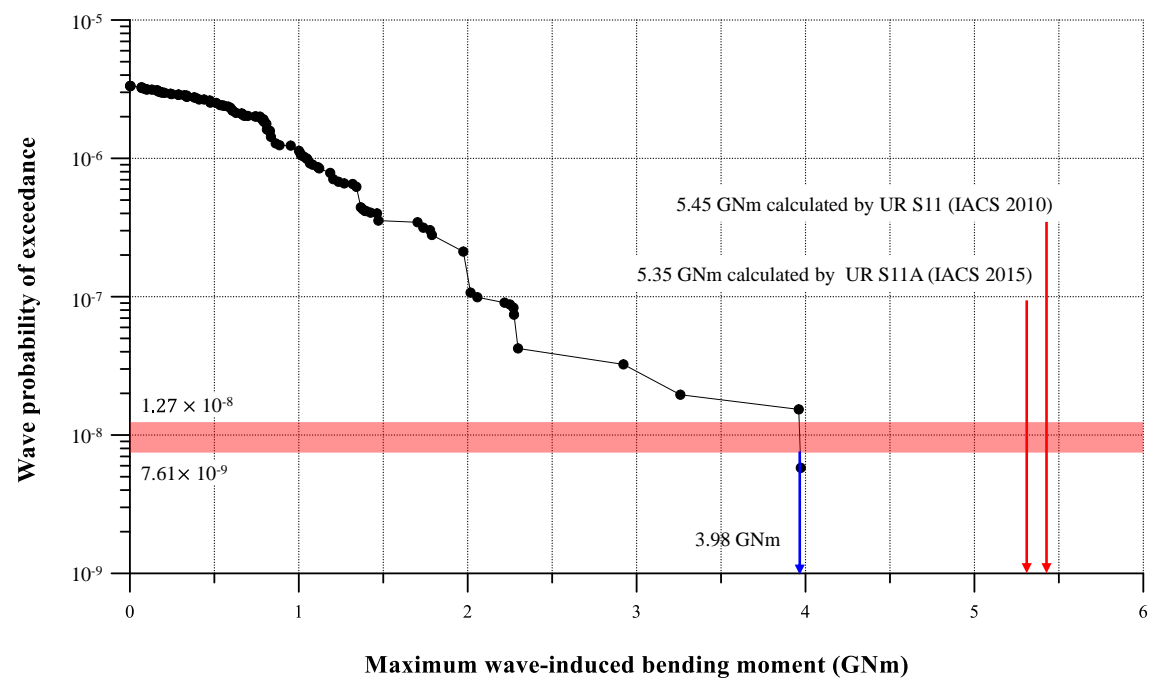

Figure 19. Wave probability of exceedance associated with the maximum hogging wave-induced bending moments for the example 9,300 TEU containership in the full load condition.

\section{Application to an as-built 22,000 TEU Containership}

The same method described in Sections 2 or 3 is now applied to determine the wave-induced design loads of an as-built 22,000 TEU containership. Table 11 indicates the principal dimensions of the example containership. Figure 20 shows the three-dimensional finite element analysis model of the entire ship.

Table 11. Principal dimensions of the example 22,000 TEU containership.

\begin{tabular}{ll}
\hline Parameter & Dimension \\
\hline Length between perpendiculars $\left(L_{B P}\right)$ & $413.0 \mathrm{~m}$ \\
Length on summer load waterline $\left(L_{L W L}\right)$ & $415.2 \mathrm{~m}$ \\
Breadth $(B)$ & $58.6 \mathrm{~m}$ \\
Depth $(D)$ & $35.1 \mathrm{~m}$ \\
Scantling draught $\left(d_{s}\right)$ & $16.5 \mathrm{~m}$ \\
Design draught $\left(d_{d}\right)$ & $14.5 \mathrm{~m}$ \\
Block coefficient $\left(C_{b}\right)$ & 0.61 \\
Waterplane coefficient $\left(C_{w}\right)$ & 0.78 \\
Design speed & $24.0 \mathrm{knot}$ \\
\hline
\end{tabular}

(a) Overall view 


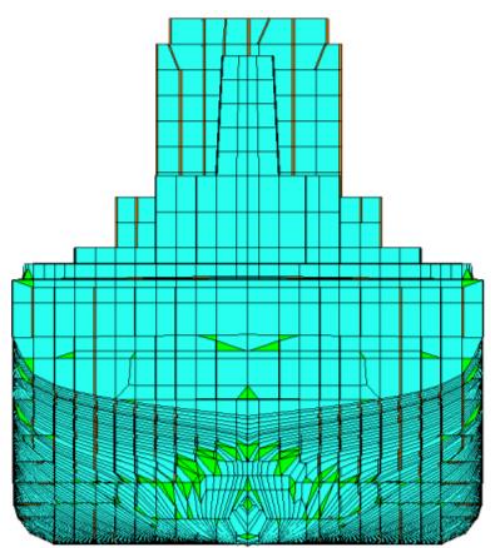

(b) Body plan view

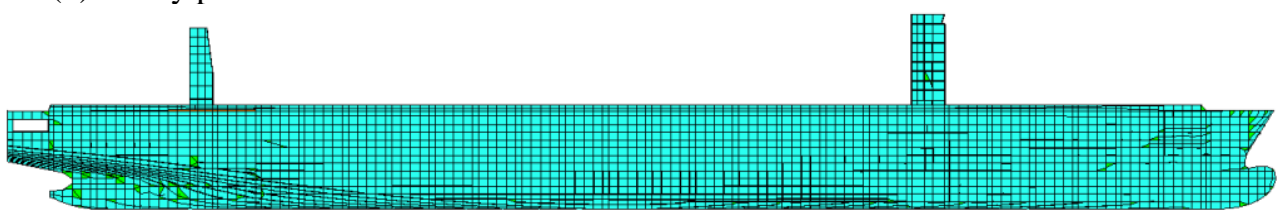

(c) Profile view

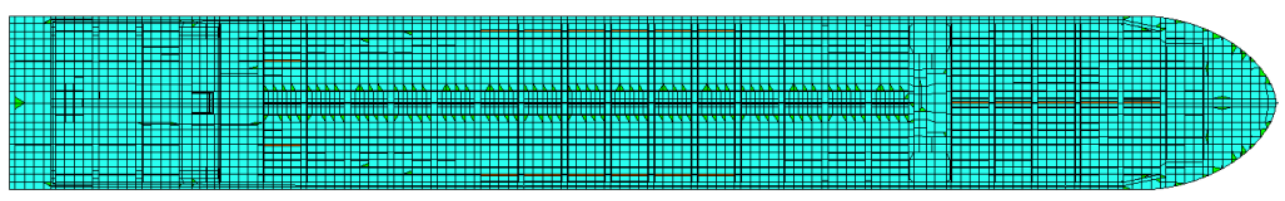

(c) Plan view

Figure 20. Three-dimensional FEA model of the example 22,000 TEU containership.

As containerships are predominantly in hogging at the full load condition, the IACS (2010) formula of Equation (6) gives the hogging wave-induced design vertical bending moment of the example 22,000 TEU containership as follows:

$$
M_{w}=+11.051 \mathrm{GNm}
$$

In contrast, the IACS formula (2015) of Equation (8) gives a larger value by $19.5 \%$ than the IACS (2010) formula of Equation (6) in hogging condition as follows:

$$
M_{w}=+13.205 \mathrm{GNm}
$$

where $L=402.713 \mathrm{~m}, B=58.6 \mathrm{~m}, d_{s}=16.5 \mathrm{~m}, C_{b}=0.61, C_{w}=0.78, f_{R}=0.85$,

$$
\begin{aligned}
& L_{r e f}=315 C_{w}^{-1.3}=415.168 \mathrm{~m}, C=1.0-1.5\left(1-\sqrt{\frac{L}{L_{r e f}}}\right)^{2.2}=0.99873, f_{N L-H o g}=0.3 \frac{C_{b}}{C_{w}} \sqrt{d_{s}}=0.955, \\
& f_{N L-S a g}=4.5 \frac{1.0+0.2 f_{b o w}}{C_{w} \sqrt{C_{b}} L^{0.3}}=1.688, f_{\text {bow }}=\frac{A_{D K}-A_{W L}}{0.2 L z_{f}}=\frac{4182.899-2132.548}{0.2 \times 449.0 \times 343.0 \times 18.82}=1.8776 .
\end{aligned}
$$

To predict the wave-induced structural loads of the example 22,000 TEU containership using the same procedure described in Figure 3, the exact same set of the wave event scenarios as for the VLCC class tanker indicated in Table 3 can also be applied. Figure 21 shows the wave elevations of selected scenarios for the 22,000 TEU containership. Table 12 indicates the maximum hogging wave-induced bending moment components for individual wave event scenarios. Figure 22 shows the distributions of the total and wave-induced vertical bending moments of the example 22,000 TEU containership, for selected wave scenarios, along the example ship's length. Figure 23 shows the probability density distribution of the maximum hogging wave-induced bending moments and its best approximation by the two-parameter log-logistic distribution which is given as follows: 


$$
f(x)=\frac{\beta}{\alpha}\left(\frac{x}{\alpha}\right)^{\beta-1}\left[1+\left(\frac{x}{\alpha}\right)^{\beta}\right]^{-2}
$$

where $\alpha=0.0757$ and $\beta=0.5506$.

Figure 24 shows the wave probability of exceedance associated with the maximum hogging waveinduced bending moments for the example 22,000 TEU containership. The present method gives 6.77 $\mathrm{GNm}$ for the design value in association with the acceptance criteria of exceedance probability in the range of $7.61 \times 10^{-9}-1.27 \times 10^{-8}$, which is $48.8 \%$ lower than the IACS (2015) formula estimation of Equation (8).

The total vertical bending moment obtained by the proposed method with the direction calculation of the still-water bending moment is smaller than the IACS rule predictions with the direction calculation of the still-water bending moment by $13.87 \%$ and it is greater than the proposed method with the IACS rule value of the still-water bending moment component by $11.41 \%$, indicating that both the IACS rule predictions and the proposed method computations are still in reasonably good agreement in the total vertical bending moments.

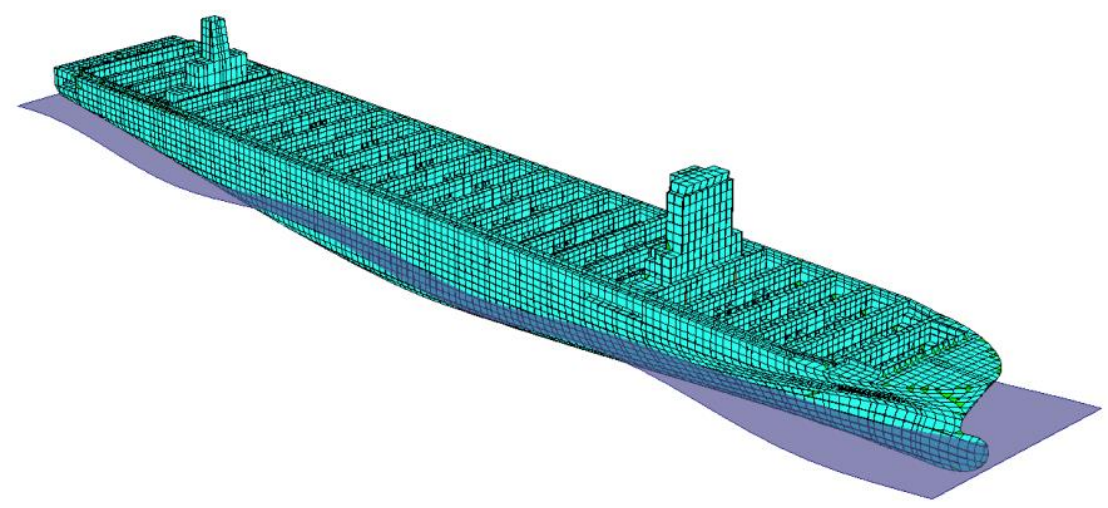

(a) Scenario 50 at wave direction of 9 deg. and phase angle of 0 deg.

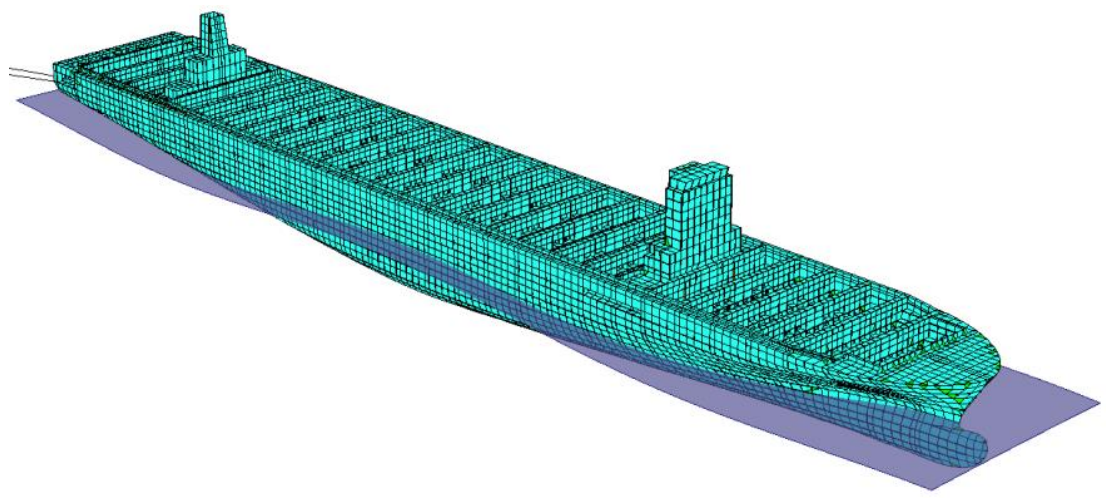

(b) Scenario 76 wave direction of 203.4 deg. and phase angle of 90 deg.

Figure 21. Wave elevations of selected scenarios for the example 22,000 TEU containership.

Table 12. Maximum hogging wave-induced bending moment components of the example 22,000 TEU containership for individual wave event scenarios in the full load condition.

\begin{tabular}{ll|ll|ll|ll}
\hline $\begin{array}{l}\text { Scenario } \\
\text { No. }\end{array}$ & $\begin{array}{l}\text { Max. V.B.M. } \\
(\mathrm{GNm})\end{array}$ & $\begin{array}{l}\text { Scenario } \\
\text { No. }\end{array}$ & $\begin{array}{l}\text { Max. V.B.M. } \\
(\mathrm{GNm})\end{array}$ & $\begin{array}{l}\text { Scenario } \\
\text { No. }\end{array}$ & $\begin{array}{l}\text { Max. V.B.M. } \\
(\mathrm{GNm})\end{array}$ & $\begin{array}{l}\text { Scenario } \\
\text { No. }\end{array}$ & $\begin{array}{l}\text { Max. V.B.M. } \\
(\mathrm{GNm})\end{array}$ \\
\hline 1 & 0.685 & 26 & 1.580 & 51 & 0.735 & 76 & 7.618 \\
2 & 0.391 & 27 & 1.172 & 52 & 0.594 & 77 & 0.773 \\
3 & 1.995 & 28 & 0.510 & 53 & 1.131 & 78 & 0.994
\end{tabular}




\begin{tabular}{ll|ll|ll|ll}
4 & 3.912 & 29 & 1.819 & 54 & 0.158 & 79 & 0.798 \\
5 & 2.486 & 30 & 0.149 & 55 & 3.177 & 80 & 0.462 \\
6 & 0.739 & 31 & 0.907 & 56 & 1.614 & 81 & 1.573 \\
7 & 0.001 & 32 & 3.671 & 57 & 3.345 & 82 & 1.471 \\
8 & 10.878 & 33 & 0.820 & 58 & 0.767 & 83 & 0.592 \\
9 & 0.486 & 34 & 4.380 & 59 & 0.300 & 84 & 2.095 \\
10 & 1.407 & 35 & 1.190 & 60 & 1.516 & 85 & 0.570 \\
11 & 3.319 & 36 & 0.953 & 61 & 2.479 & 86 & 1.226 \\
12 & 4.013 & 37 & 0.193 & 62 & 0.316 & 87 & 5.314 \\
13 & 0.948 & 38 & 0.420 & 63 & 1.211 & 88 & 0.820 \\
14 & 1.319 & 39 & 4.245 & 64 & 0.026 & 89 & 0.403 \\
15 & 1.332 & 40 & 1.889 & 65 & 0.709 & 90 & 0.735 \\
16 & 0.844 & 41 & 0.420 & 66 & 5.419 & 91 & 2.572 \\
17 & 4.583 & 42 & 2.039 & 67 & 3.164 & 92 & 0.285 \\
18 & 4.847 & 43 & 0.605 & 68 & 3.927 & 93 & 1.688 \\
19 & 0.109 & 44 & 2.695 & 69 & 2.171 & 94 & 0.416 \\
20 & 0.814 & 45 & 1.856 & 70 & 0.303 & 95 & 0.508 \\
21 & 1.333 & 46 & 6.202 & 71 & 3.367 & 96 & 0.496 \\
22 & 0.991 & 47 & 0.783 & 72 & 2.680 & 97 & 0.087 \\
23 & 0.149 & 48 & 0.482 & 73 & 0.981 & 98 & 0.190 \\
24 & 0.660 & 49 & 1.645 & 74 & 1.605 & 99 & 5.459 \\
25 & 4.682 & 50 & 2.954 & 75 & 0.759 & 100 & 2.897 \\
\hline
\end{tabular}

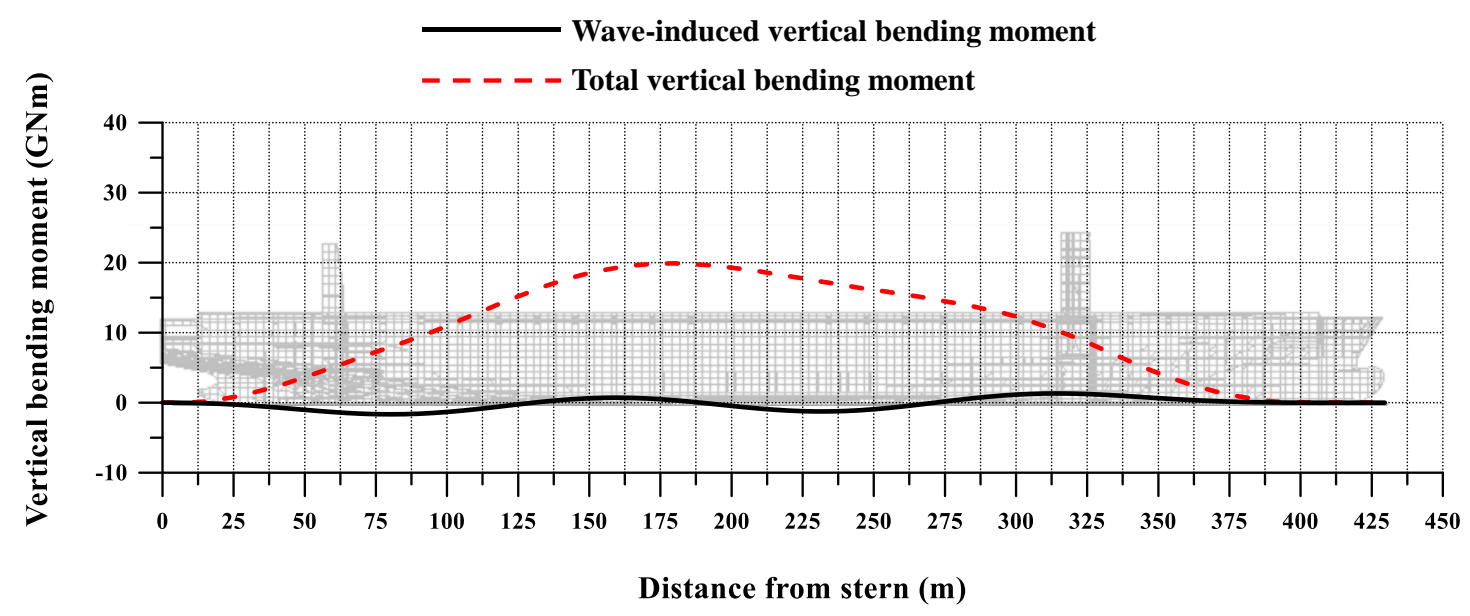

(a) Scenario 50 at wave direction of $9 \mathrm{deg}$. and phase angle of $0 \mathrm{deg}$. 


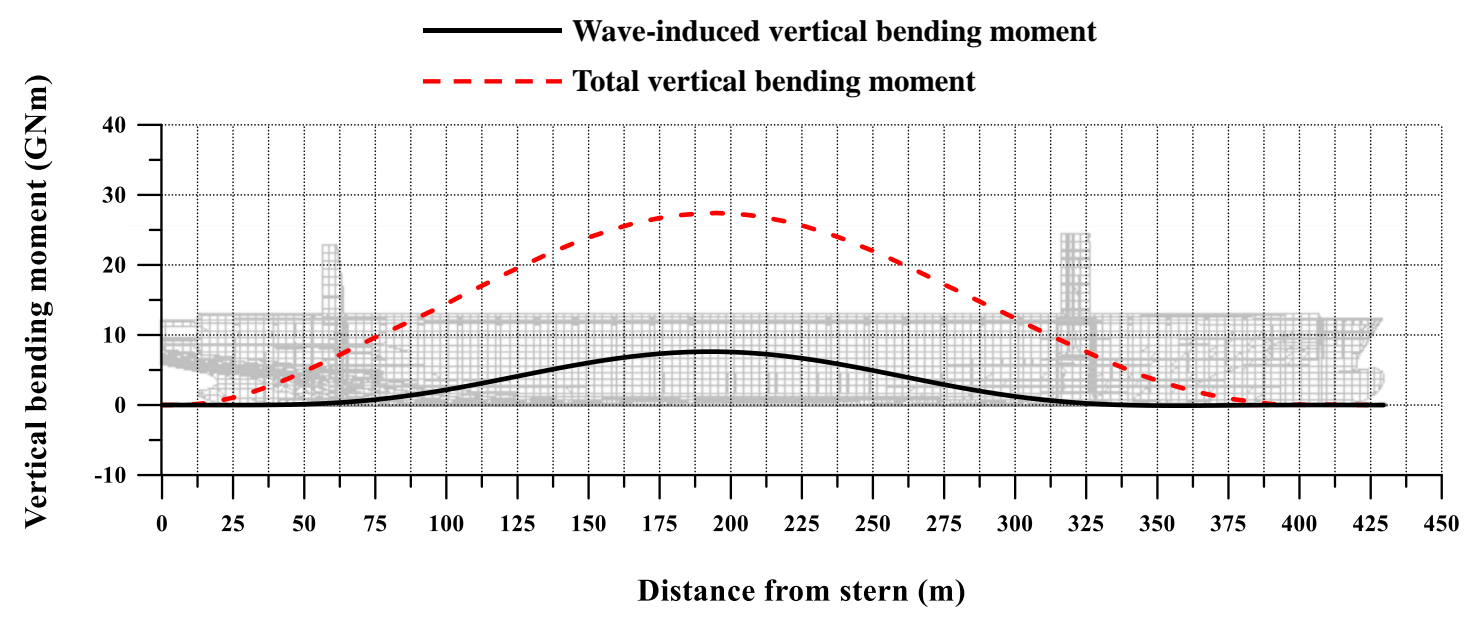

(b) Scenario 76 wave direction of $203.4 \mathrm{deg}$. and phase angle of $90 \mathrm{deg}$.

Figure 22. Distributions of total and wave-induced vertical bending moments of the example 22,000 TEU containership for selected wave scenarios in the full load condition.

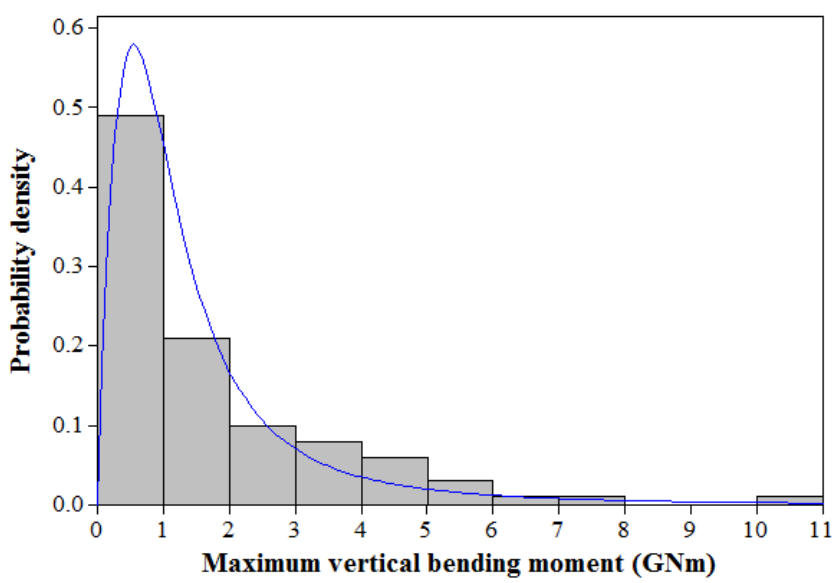

Figure 23. Distribution of the maximum hogging wave-induced bending moments and its best approximation by the two-parameter log-logistic function, Equation (14), obtained by MAESTRO computations for the example 22,000 TEU containership.

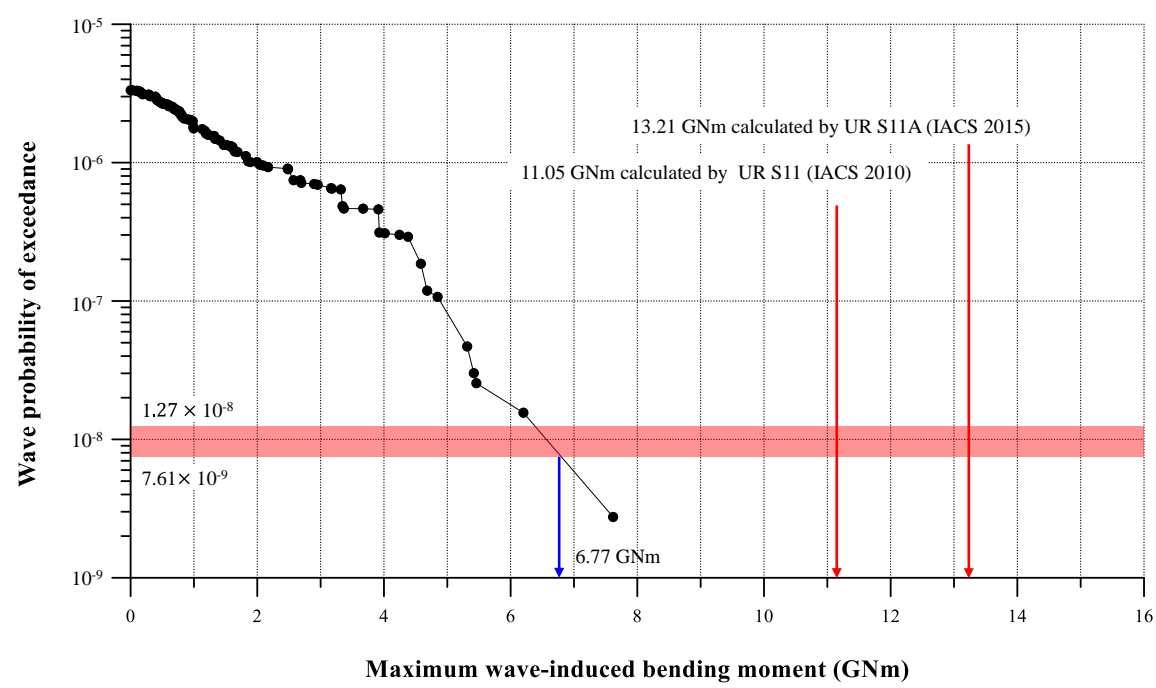

Figure 24. Wave probability of exceedance associated with the maximum hogging wave-induced bending moments for the example 22,000 TEU containership in the full load condition. 


\section{Application to a hypothetical 25,000 TEU Containership}

The same method described in Sections 2, 3 or 4 is now applied to determine the wave-induced design loads of a hypothetical 25,000 TEU containership. Table 13 provides the principal dimensions of the example containership. Figure 25 shows the three-dimensional FEA model of the entire ship.

Table 13. Principal dimensions of the example 25,000 TEU containership.

\begin{tabular}{ll}
\hline Parameter & Dimension \\
\hline Length between perpendiculars $\left(L_{B P}\right)$ & $460.8 \mathrm{~m}$ \\
Length on summer load waterline $\left(L_{L W L}\right)$ & $463.2 \mathrm{~m}$ \\
Breadth $(B)$ & $58.6 \mathrm{~m}$ \\
Depth $(D)$ & $35.1 \mathrm{~m}$ \\
Scantling draught $\left(d_{s}\right)$ & $16.3 \mathrm{~m}$ \\
Design draught $\left(d_{d}\right)$ & $14.3 \mathrm{~m}$ \\
Block coefficient $\left(C_{b}\right)$ & 0.64 \\
Waterplane coefficient $\left(C_{w}\right)$ & 0.80 \\
Design speed & $24.0 \mathrm{knot}$ \\
\hline
\end{tabular}

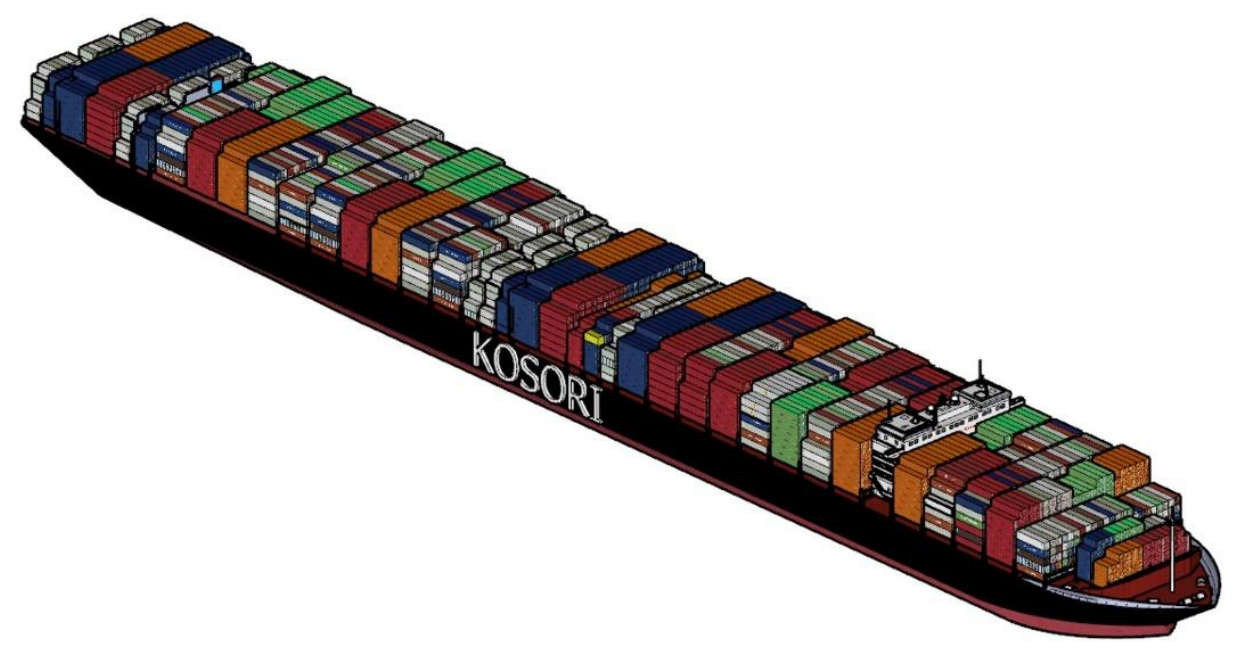

Figure 25(a). A hypothetical 25,000 TEU containership.

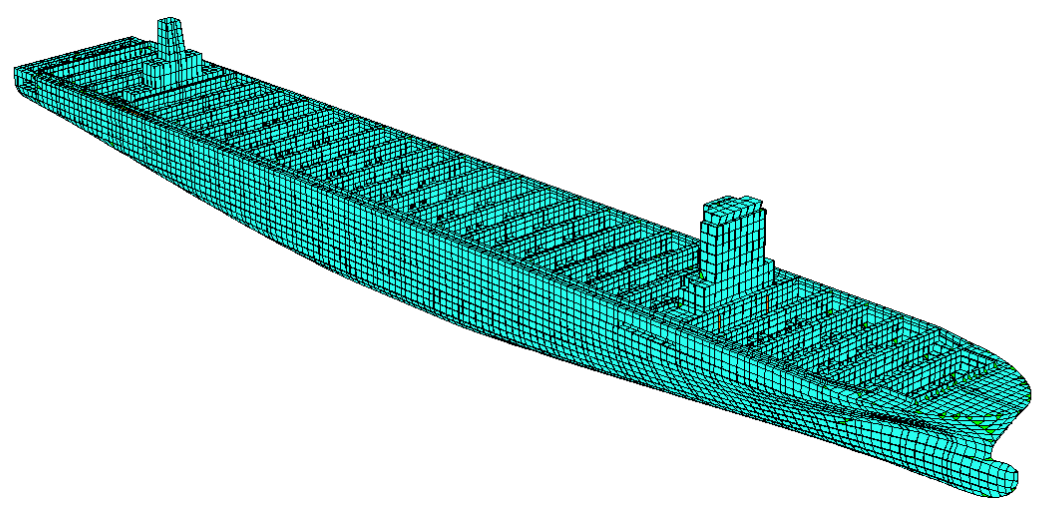


(a) Overall view

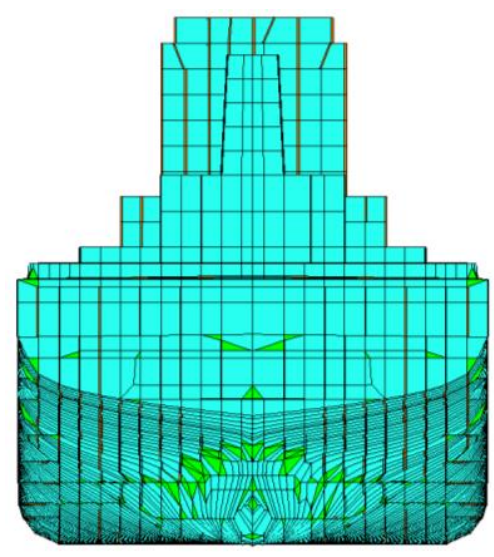

(b) Body plan view

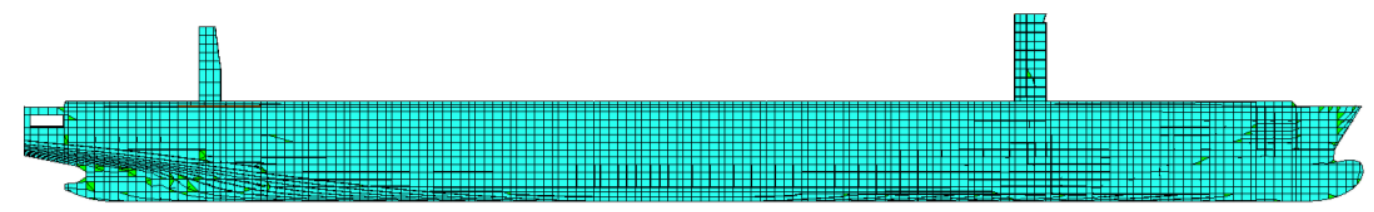

(c) Profile view

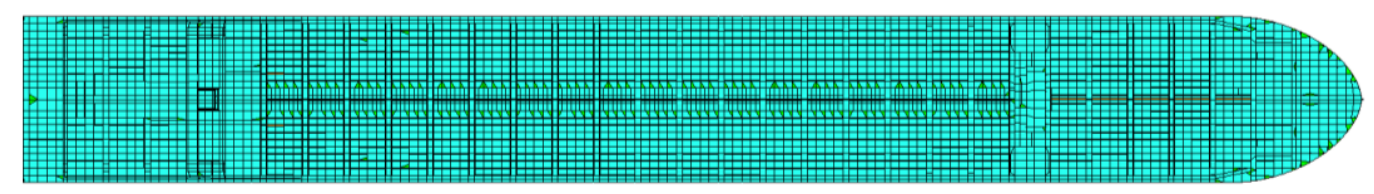

(d) Plan view

Figure 25(b). Three-dimensional finite element analysis model of the example 25,000 TEU containership.

Similar to the 9,300 TEU and 22,000 TEU containerships, hogging dominates in the full load condition for the 25,000 TEU containership. The IACS (2010) formula of Equation (6) then gives the hogging wave-induced design vertical bending moment of the example 25,000 TEU containership as follows:

$$
M_{w}=+14.389 \mathrm{GNm}
$$

On the other hand, the IACS (2015) formula of Equation (8) gives a larger value by $19.5 \%$ than the IACS (2010) formula of Equation (6) in hogging condition as follows:

$$
M_{w}=+17.522 \mathrm{GNm}
$$

where $L=449.343 \mathrm{~m}, B=58.6 \mathrm{~m}, d_{s}=16.3 \mathrm{~m}, C_{b}=0.64, C_{w}=0.80, f_{R}=0.85$,

$$
\begin{aligned}
& L_{r e f}=315 C_{w}^{-1.3}=419.992 \mathrm{~m}, C=1.0-1.5\left(1-\sqrt{\frac{L}{L_{r e f}}}\right)^{2.2}=0.99854, f_{N L-H o g}=0.3 \frac{C_{b}}{C_{w}} \sqrt{d_{s}}=0.966, \\
& f_{N L-S a g}=4.5 \frac{1.0+0.2 f_{\text {bow }}}{C_{w} \sqrt{C_{b}} L^{0.3}}=1.397, f_{\text {bow }}=\frac{A_{D K}-A_{W L}}{0.2 L z_{f}}=\frac{4182.899-2132.548}{0.2 \times 449.0 \times 343.0 \times 18.82}=1.2123 .
\end{aligned}
$$


To predict the wave-induced structural loads of the example 25,000 TEU containership, using the same procedure described in Figure 3, the exactly same set of the wave event scenarios as for the VLCC class tanker indicated in Table 3 can also be applied. Figure 26 shows the wave elevations of the selected scenarios for the 25,000 TEU containership. Table 14 indicates the maximum hogging waveinduced bending moment components for individual wave event scenarios. Figure 27 shows the distributions of the total and wave-induced vertical bending moments of the example 25,000 TEU containership for selected wave scenarios along the example ship's length. Figure 28 shows the probability density distribution of the maximum hogging wave-induced bending moments and its best approximation by the three-parameter lognormal distribution which is give as follows:

$$
f(x)=\frac{1}{(x-\gamma) \sqrt{2 \pi} \beta} \exp \left[\frac{-\{\ln (x-\gamma)-\alpha\}^{2}}{2 \beta^{2}}\right]
$$

where $\alpha=0.9237, \beta=0.6273$ and $\gamma=0.1994$.

Figure 29 shows the wave probability of exceedance associated with the maximum hogging waveinduced bending moments for the example 25,000 TEU containership. The present method gives 8.61 GNm for the design value in association with the acceptance criteria of exceedance probability in the range of $7.61 \times 10^{-9}-1.27 \times 10^{-8}$, which is $50.9 \%$ lower than the IACS (2015) formula estimation of Equation (8). Figure 30 compares the wave probability of exceedance associated with the maximum hogging wave-induced bending moments for the three different sizes of containership.

The total vertical bending moment obtained by the proposed method with the direction calculation of the still-water bending moment is smaller than the IACS rule predictions with the direction calculation of the still-water bending moment by $15.93 \%$ and it is greater than the proposed method with the IACS rule value of the still-water bending moment component by $2.07 \%$, indicating that both the IACS rule predictions and the proposed method computations are still in reasonably good agreement in the total vertical bending moments.

Figure 31 shows the variation of the design hogging wave-induced vertical bending moments of containerships in the full load condition with varying TEU capacity. It is obvious that the design hogging wave-induced bending moments significantly increase as the ship size increases. It is seen that the ascending trend of the design wave-induced moments is exponential. The IACS rule predictions are based on a totally different approach from the present method in that the former defines a design wave and the wave-induced hull girder loads are calculated in association with the predefined design wave. Regardless of this, it is interesting to note that both methods give similar results of the wave-induced hull girder load predictions for a particular containership with a comparatively small TEU capacity, while significant differences between the IACS formula prediction and the proposed method are found for ultra-large containerships.

On the other hand, Figure 32 and Table 15 present the comparisons of the total bending moments between the IACS formula predictions and the proposed method computations where the proposed method computations always use the still-water bending moment component directly calculated from the loading conditions, while the IACS case studies use either the direction calculations from the loading conditions or the IACS formula predictions.

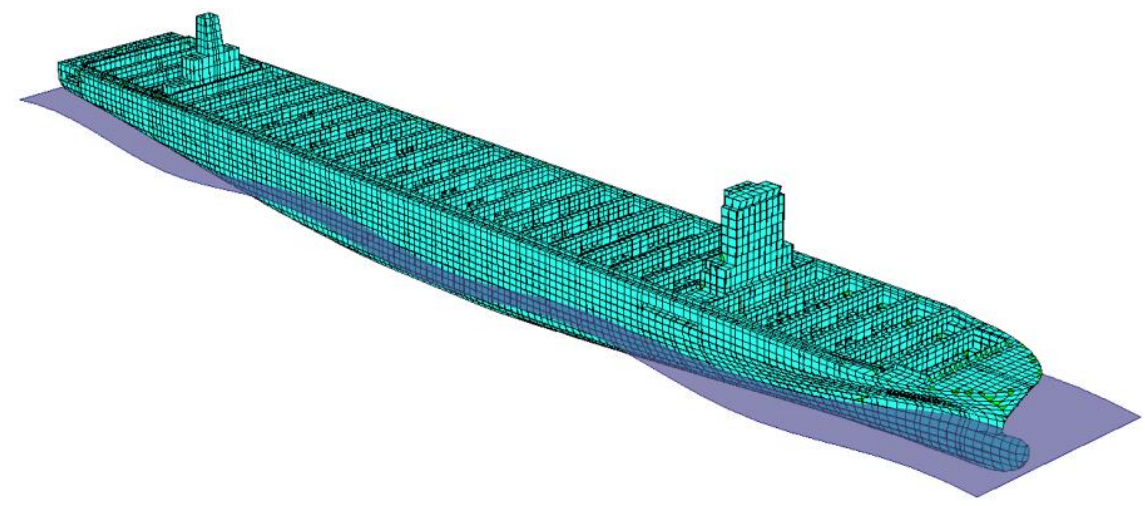

(a) Scenario 50 at wave direction of $9 \mathrm{deg}$. and phase angle of $0 \mathrm{deg}$. 


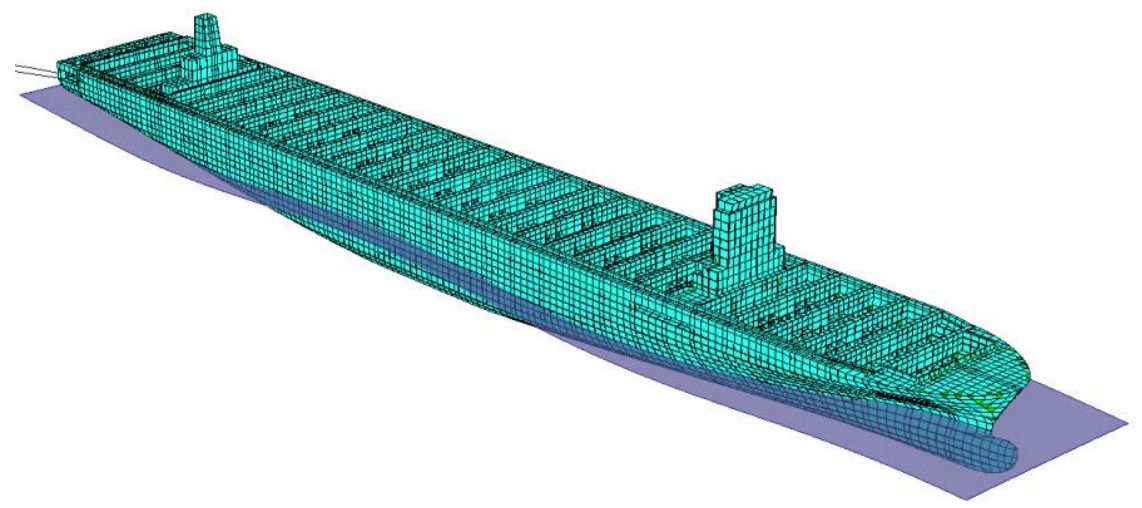

(b) Scenario 76 wave direction of $203.4 \mathrm{deg}$. and phase angle of $90 \mathrm{deg}$.

Figure 26. Wave elevations of selected scenarios for the example 25,000 TEU containership.

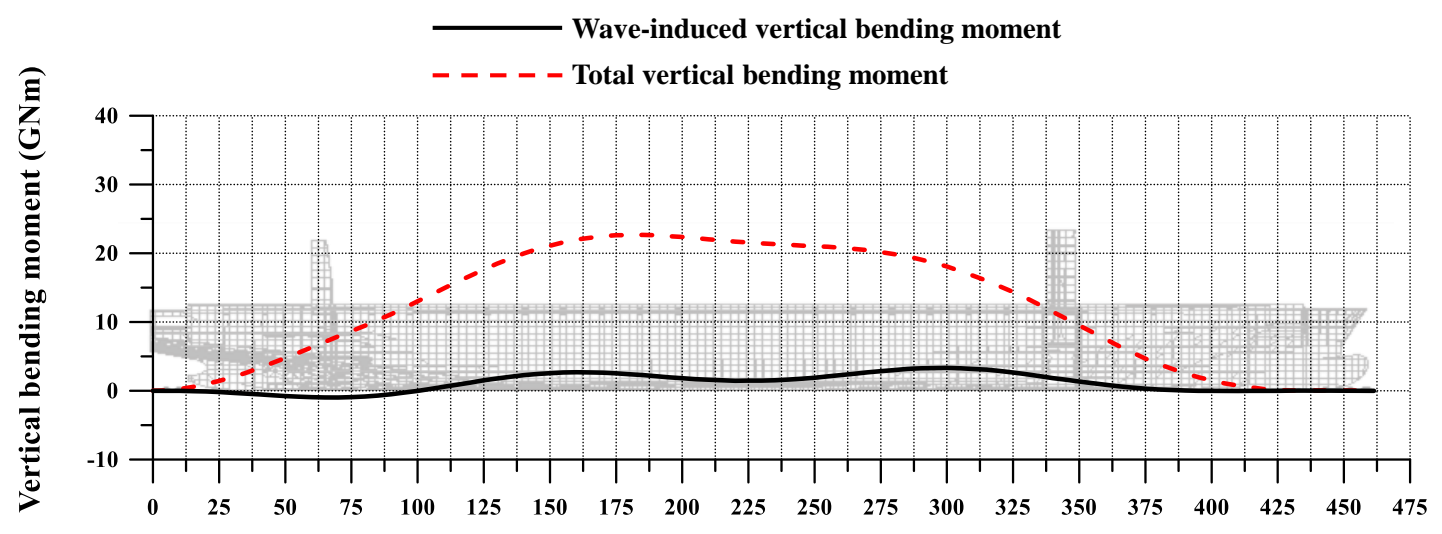

Distance from stern $(m)$

(a) Scenario 50 at wave direction of $9 \mathrm{deg}$. and phase angle of $0 \mathrm{deg}$.

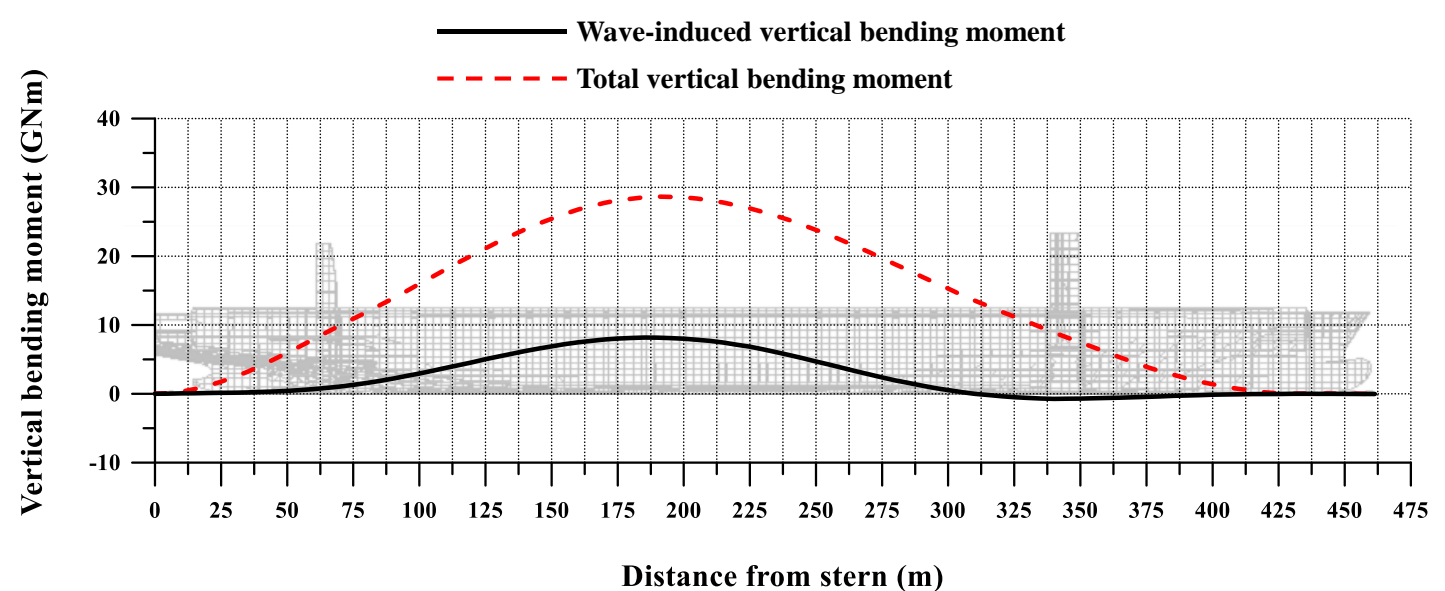

(b) Scenario 76 wave direction of $203.4 \mathrm{deg}$. and phase angle of $90 \mathrm{deg}$.

Figure 27. Distributions of total and wave-induced vertical bending moments of the example 25,000 TEU containership for selected wave scenarios in the full load condition.

Table 14. Maximum hogging wave-induced bending moment components of the example 25,000 TEU containership for individual wave event scenarios in the full load condition.

\begin{tabular}{ll|ll|ll|ll}
\hline $\begin{array}{l}\text { Scenario } \\
\text { No. }\end{array}$ & $\begin{array}{l}\text { Max. V.B.M. } \\
(\text { GNm) }\end{array}$ & $\begin{array}{l}\text { Scenario } \\
\text { No. }\end{array}$ & $\begin{array}{l}\text { Max. V.B.M. } \\
(\text { GNm })\end{array}$ & $\begin{array}{l}\text { Scenario } \\
\text { No. }\end{array}$ & $\begin{array}{l}\text { Max. V.B.M. } \\
(\text { GNm })\end{array}$ & $\begin{array}{l}\text { Scenario } \\
\text { No. }\end{array}$ & $\begin{array}{l}\text { Max. V.B.M. } \\
(\text { GNm })\end{array}$ \\
\hline
\end{tabular}




\begin{tabular}{|c|c|c|c|c|c|c|c|}
\hline 1 & 2.128 & 26 & 3.421 & 51 & 1.600 & 76 & 8.177 \\
\hline 2 & 1.262 & 27 & 2.034 & 52 & 2.332 & 77 & 2.055 \\
\hline 3 & 3.123 & 28 & 1.892 & 53 & 2.283 & 78 & 2.283 \\
\hline 4 & 5.206 & 29 & 2.341 & 54 & 1.233 & 79 & 1.300 \\
\hline 5 & 4.504 & 30 & 1.234 & 55 & 4.124 & 80 & 1.640 \\
\hline 6 & 2.479 & 31 & 2.057 & 56 & 2.664 & 81 & 2.120 \\
\hline 7 & 1.041 & 32 & 6.104 & 57 & 6.173 & 82 & 2.387 \\
\hline 8 & 14.162 & 33 & 1.632 & 58 & 2.469 & 83 & 1.339 \\
\hline 9 & 2.151 & 34 & 6.709 & 59 & 1.617 & 84 & 2.516 \\
\hline 10 & 2.444 & 35 & 2.176 & 60 & 3.063 & 85 & 1.347 \\
\hline 11 & 5.068 & 36 & 2.503 & 61 & 2.992 & 86 & 3.058 \\
\hline 12 & 5.056 & 37 & 1.225 & 62 & 1.629 & 87 & 8.622 \\
\hline 13 & 2.696 & 38 & 0.841 & 63 & 2.318 & 88 & 2.309 \\
\hline 14 & 2.507 & 39 & 4.734 & 64 & 1.220 & 89 & 1.327 \\
\hline 15 & 2.566 & 40 & 2.398 & 65 & 1.757 & 90 & 1.603 \\
\hline 16 & 1.788 & 41 & 1.591 & 66 & 7.155 & 91 & 4.667 \\
\hline 17 & 5.640 & 42 & 4.050 & 67 & 4.921 & 92 & 1.298 \\
\hline 18 & 7.502 & 43 & 2.432 & 68 & 6.261 & 93 & 3.440 \\
\hline 19 & 1.038 & 44 & 3.757 & 69 & 5.054 & 94 & 1.838 \\
\hline 20 & 2.208 & 45 & 4.168 & 70 & 1.375 & 95 & 2.352 \\
\hline 21 & 2.622 & 46 & 6.311 & 71 & 6.203 & 96 & 1.375 \\
\hline 22 & 2.347 & 47 & 2.136 & 72 & 4.110 & 97 & 1.244 \\
\hline 23 & 1.261 & 48 & 1.333 & 73 & 2.114 & 98 & 1.258 \\
\hline 24 & 2.343 & 49 & 2.992 & 74 & 2.890 & 99 & 9.387 \\
\hline 25 & 7.667 & 50 & 3.335 & 75 & 2.223 & 100 & 4.614 \\
\hline
\end{tabular}

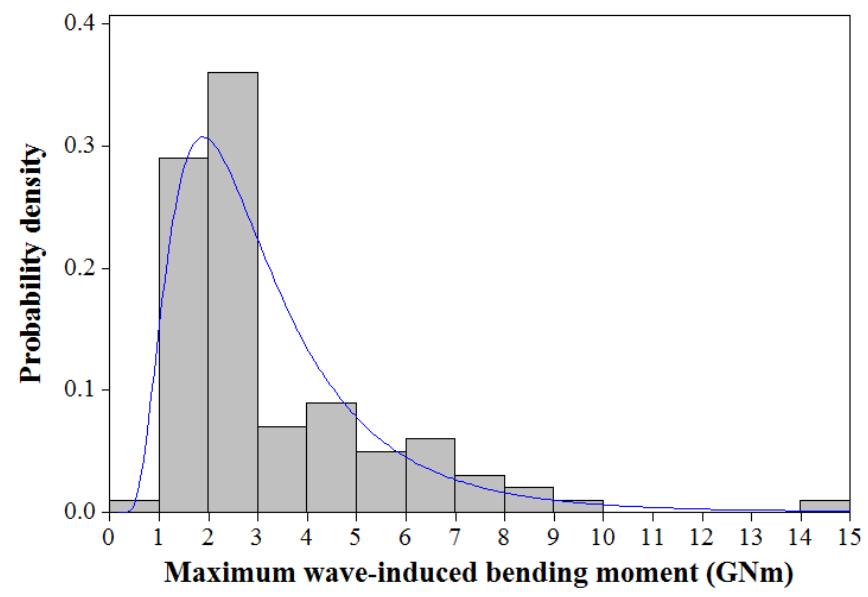

Figure 28. Distribution of the maximum hogging wave-induced bending moments and its best approximation by the three-parameter lognormal function, Equation (17), obtained by MAESTRO computations for the example 25,000 TEU containership in the full load condition. 


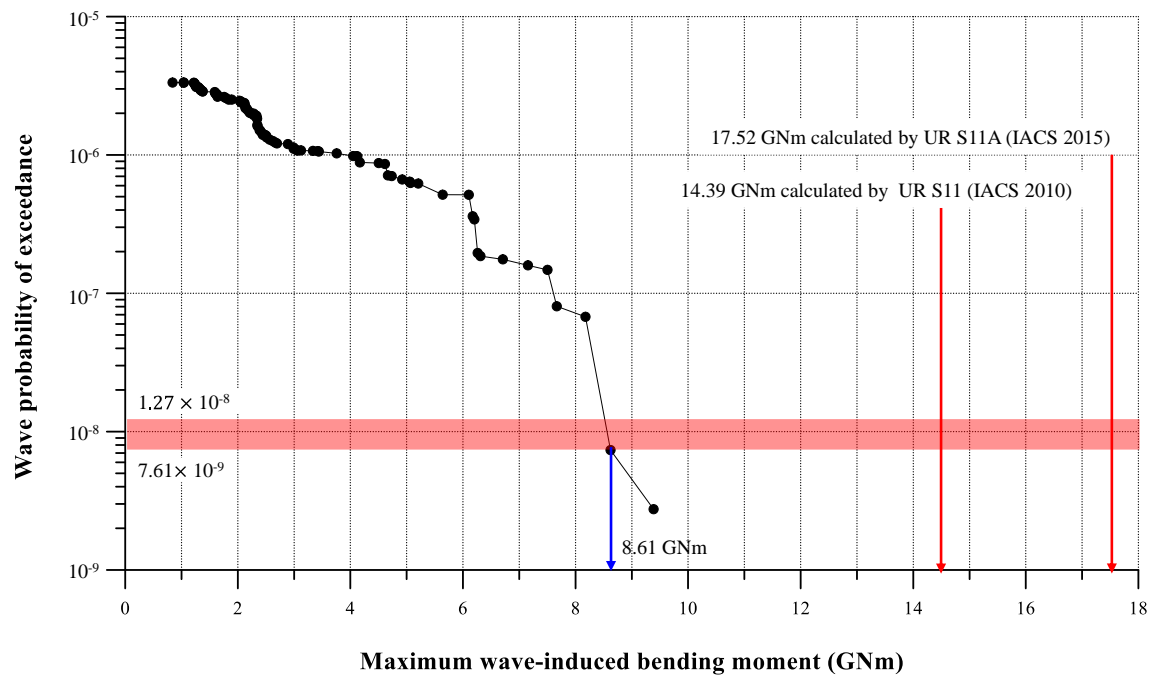

Figure 29. Wave probability of exceedance associated with the maximum hogging wave-induced bending moments for the example 25,000 TEU containership in the full load condition.

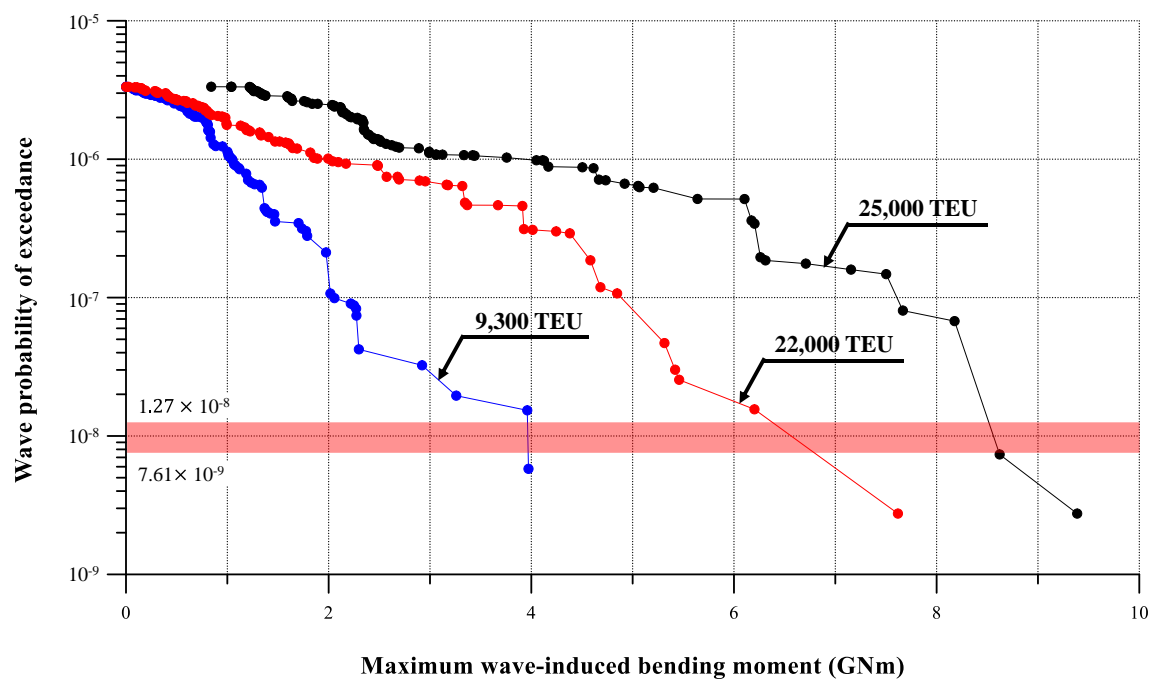

Figure 30. Comparison of the maximum hogging wave-induced bending moments for three different sizes of the containerships.

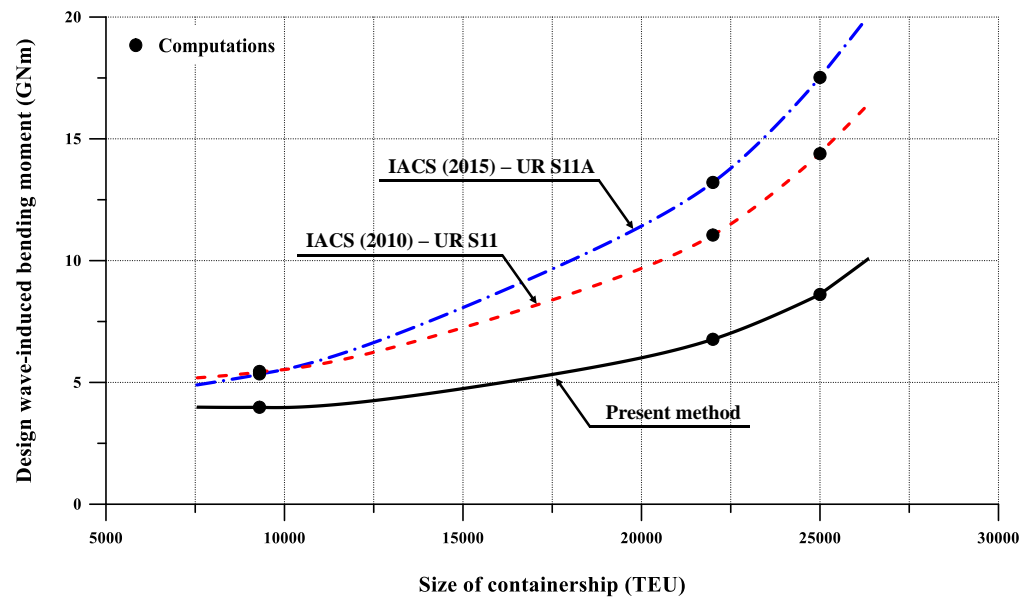


Figure 31. Variation of the maximum hogging wave-induced bending moments for containerships in the full load condition.

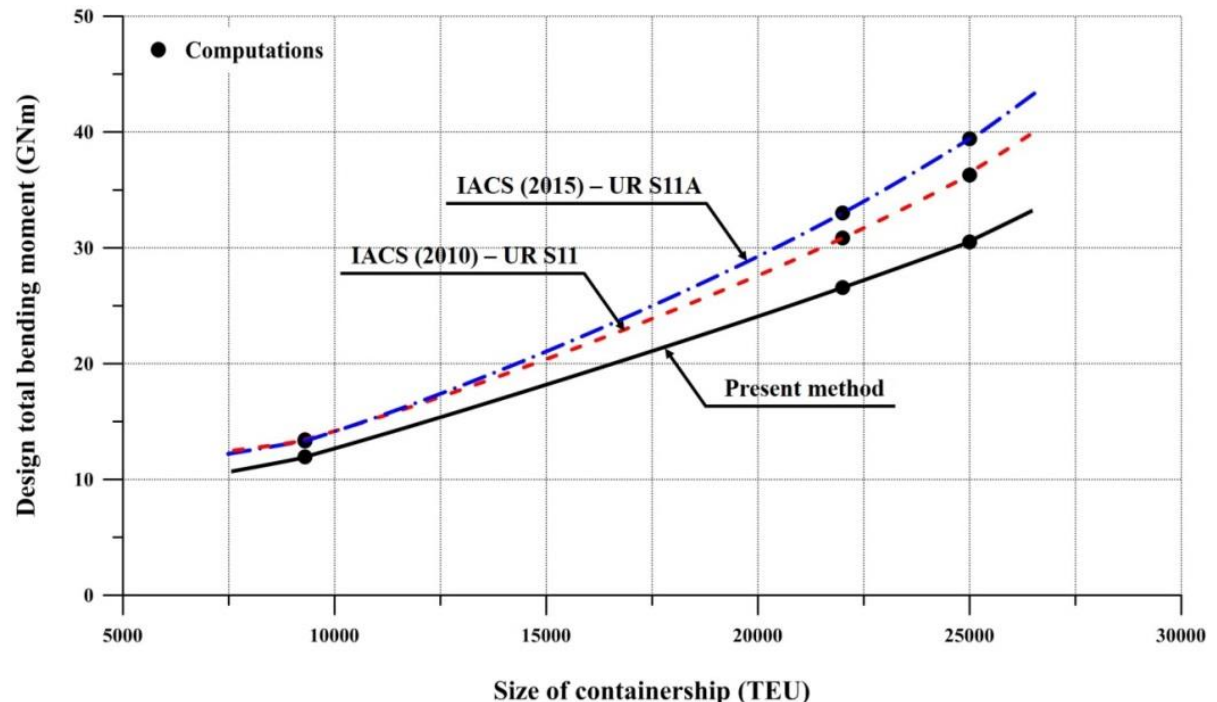

Figure 32(a). Variation of the maximum total hogging bending moments for containerships in the full load condition, with the direction calculations of the still-water bending moment component.

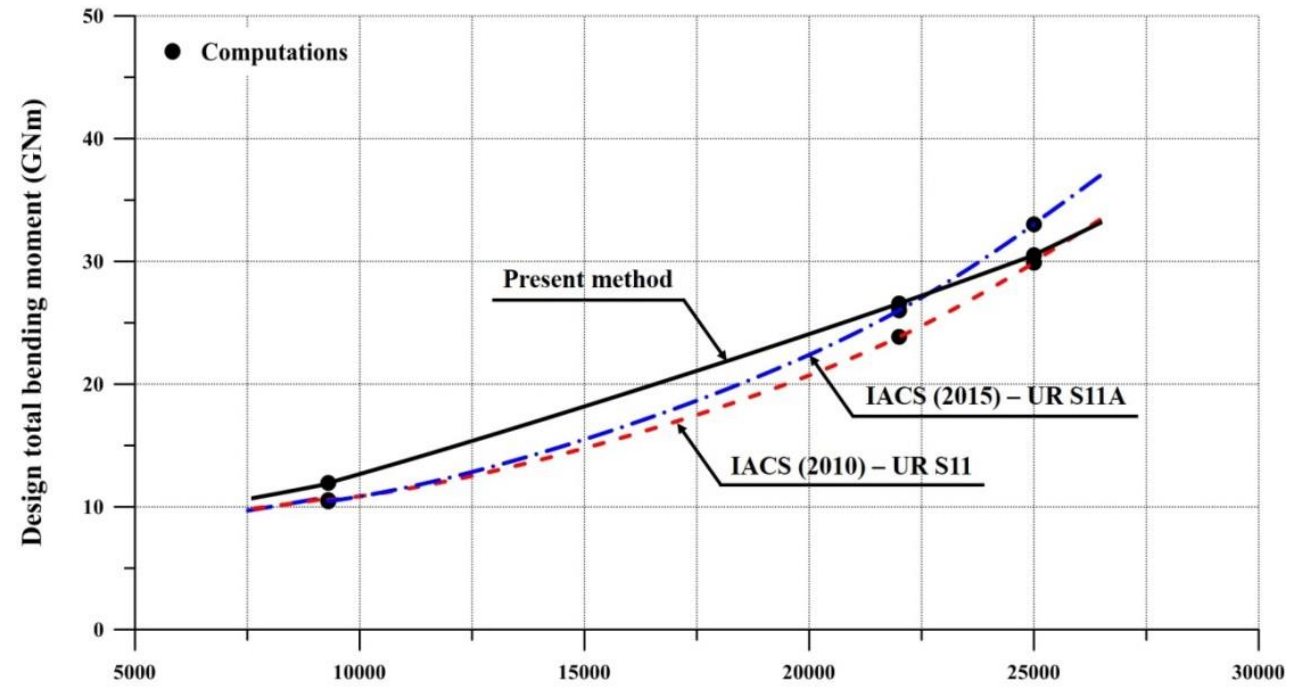

Size of containership (TEU)

Figure 32(b). Variation of the maximum total hogging bending moments for containerships in the full load condition, with the IACS formula predictions of the still-water bending moment component for the IACS rule case.

Table 15. Design values of maximum bending moment computations for a VLCC class tanker and various sizes of containerships.

\begin{tabular}{c|cc|ccc|ccccc}
\hline \multirow{2}{*}{$\begin{array}{c}\text { Ship } \\
\text { type }\end{array}$} & \multicolumn{2}{|c|}{$\mathrm{M}_{\mathrm{s}}(\mathrm{GNm})$} & \multicolumn{3}{c|}{$\mathrm{M}_{\mathrm{w}}(\mathrm{GNm})$} & \multicolumn{5}{c}{ Mt $(\mathrm{GNm})$} \\
\cline { 2 - 10 } & $\begin{array}{c}\text { Direct, } \\
\mathrm{M}_{\mathrm{s} 1}\end{array}$ & $\begin{array}{c}\text { IACS, } \\
\mathrm{M}_{\mathrm{s} 2}\end{array}$ & $\begin{array}{c}\text { Present } \\
\text { method }\end{array}$ & $\begin{array}{c}\text { IACS } \\
(2010)\end{array}$ & $\begin{array}{c}\text { IACS } \\
(2015)\end{array}$ & $\begin{array}{c}\text { Present } \\
\text { method }\end{array}$ & $\begin{array}{c}\text { IACS[1] } \\
(2010)\end{array}$ & $\begin{array}{c}\text { IACS[2] } \\
(2010)\end{array}$ & $\begin{array}{c}\text { IACS[1] } \\
(2015)\end{array}$ & $\begin{array}{c}\text { IACS[2] } \\
(2015)\end{array}$ \\
\hline VLCC & -6.87 & -4.8 & -8.44 & -10.19 & - & -15.31 & -17.06 & -14.99 & - & - \\
$\begin{array}{c}9,300 \\
\text { TEU }\end{array}$ & 7.97 & 5.10 & 3.98 & 5.45 & 5.35 & 11.95 & 13.42 & 10.55 & 13.32 & 10.45
\end{tabular}




\begin{tabular}{c|cc|ccc|ccccc}
$\begin{array}{c}22,000 \\
\text { TEU }\end{array}$ & 19.80 & 12.80 & 6.77 & 11.05 & 13.21 & 26.57 & 30.85 & 23.85 & 33.01 & 26.01 \\
$\begin{array}{c}25,000 \\
\text { TEU }\end{array}$ & 21.90 & 15.50 & 8.61 & 14.39 & 17.52 & 30.51 & 36.29 & 29.89 & 39.42 & 33.02 \\
\hline
\end{tabular}

Notes: $\mathrm{M}_{\mathrm{s}}=$ still-water bending moment component, $\mathrm{M}_{\mathrm{w}}=$ wave-induced bending moment component, $\mathrm{M}_{\mathrm{t}}=\mathrm{M}_{\mathrm{s}}+\mathrm{M}_{\mathrm{w}}=$ total bending moment, "Direct" indicates that the still-water bending moment component was calculated directly for the loading condition, "negative' sign represents sagging moment, "positive" sign represents hogging moment, "Present method" always calculates the stillwater bending moment component directly for the loading condition, $\mathbf{M}_{\mathrm{s} 1}=$ still-water bending moment component directly calculated from loading condition, $\mathrm{M}_{\mathrm{s} 2}=$ still-water bending moment component calculated by the IACS rule formula, IACS[1] indicates that the still-water bending moment component is calculated by with $\mathrm{M}_{\mathrm{s} 1}$, IACS[2] indicates that the still-water bending moment component is calculated by with $\mathrm{M}_{\mathrm{s} 2}$

\section{Concluding remarks and further studies}

The aim of the present paper has been to present a new probabilistic method to determine the design values of wave-induced hull girder loads acting on ships. The method has been applied to asbuilt ships such as a VLCC class tanker, a 9,300 TEU containership and a 22,000 TEU containership, and a hypothetical 25,000 TEU containership to determine the design values of wave-induced vertical bending moments. Based on the present study, the following insights and conclusions can be drawn

(1) The present method is totally different from the traditional methods in industry in terms of predicting the design values of wave-induced hull girder loads acting on a ship. The present method defines a design wave by a probabilistic method and the wave-induced hull girder loads are calculated by seakeeping motion and load analysis in association with the predefined design wave. The IACS rule methods have been derived in closed-form expressions as a function of principal dimensions and operational parameters based on the results of the traditional method computations. On the other hand, the present method uses a sampling technique to select a set of credible wave event scenarios associated with random parameters affecting ship motions such as significant wave height (or wave amplitude), zero crossing wave period (converting to wave length) and heading angle together with wave phase angle. The seakeeping motion and load analyses are undertaken to calculate wave-induced hull girder loads for each of individual wave event scenarios selected. The exceedance curve of the wave frequency against maximum hull girder loads can be established from the seakeeping load computations and it gives the design values of wave-induced hull girder loads acting on a ship associated with relevant criteria.

(2) It is interesting to note that both the IACS rule method and the present method give similar results of the wave-induced hull girder load predictions for a particular containership with a comparatively small TEU capacity as well as the VLCC class tanker, regardless of the fact that both methods are totally different from each other. It is considered that the differences between the two methods are due to the nonlinear effects associated with irregular sea states and operating speed, etc. because the ship motion and load analyses in the applied examples of the present paper are undertaken with regular waves with nonlinear corrections for the purpose of simplicity.

(3) The VLCC class tanker hull is predominantly in sagging at the full load condition. The design value of the sagging wave-induced bending moments calculated by the present method is $17.2 \%$ lower than the IACS 2010 rule formula. The design value from the present method is determined from the wave probability of exceedance associated with the acceptance criteria in the range of $7.61 \times 10^{-9}-1.27 \times 10^{-8}$, that represents the occurrence probability of the maximum wave peak during the entire life time of the ship.

(4) Containerships are predominantly in hogging at the full load condition. The design value of the hogging wave-induced bending moments of the example 9,300 TEU containership is determined from the present method is $25.4 \%$ lower than the IACS 2015 rule formula, in association with the acceptance criteria of exceedance probability in the range of $7.61 \times 10^{-9}$ $1.27 \times 10^{-8}$.

(5) Similar applications to an as-built 22,000 TEU containership and a hypothetical 25,000 TEU 
containership in the full load condition show that the present method provides lower values of the hogging wave-induced vertical bending moments by $48.8 \%$ for the $22,000 \mathrm{TEU}$ containership and by $50.9 \%$ for the 25,000 TEU containership than the IACS 2015 rule formula predictions.

(6) As is well known, the design values of the wave-induced vertical bending moments significantly increase with an increase of ship size. The ascending trend of the wave-induced bending moments is exponential.

(7) Given the comparison of the wave-induced bending moment component, it is found that the total vertical bending moments are relatively in good agreement between the proposed method computations and the IACS formula predictions.

(8) In the present paper, the seakeeping motion and load analyses for the applied examples have been based on linear response analysis in regular waves but they do not take into account dynamic and nonlinear effects of ship motions associated with extreme waves or whipping. Further studies using nonlinear time domain simulations in random waves are recommended in this regard, although the procedure proposed in the present study may still be applicable.

(9) In the illustrative examples of the present methodology, only three parameters, namely significant wave height, wave period and wave heading angle, have been considered as random variable affecting wave actions. However, more parameters such as ship speed, wind (speed, direction) and current (speed, direction) can also be added as influential parameters as updated wave statistical database becomes available. Also, the audience of this paper is encouraged to use more refined tools for ship motion analysis at selected wave scenarios.

(10) To more accurately characterise the probabilistic density distribution characteristics of the random wave parameters, it is required to obtain more database of sea states due to climate changes.

\section{References}

ABS (2015). Guide for 'SafeHull-dynamic loading approach' for vessels. American Bureau of Shipping, Houston, USA.

Chakrabarti SK (2005). Handbook of offshore engineering (Volume 1). Elsevier Ltd., London, UK.

Hogben N, Lumb FE (1967). Ocean wave statistics. HMSO, National Physical Laboratory, London, UK.

Hughes OF, Paik JK (2013). Ship structural analysis and design. The Society of Naval Architects and Marine Engineers, Alexandria, USA.

IACS (2001). Standard wave data (REC. 34). International Association of Classification Societies, London, UK.

IACS (2010). Longitudinal strength standard (UR S11). International Association of Classification Societies, London, UK.

IACS (2015). Longitudinal strength standard for container ships (UR S11A). International Association of Classification Societies, London, UK.

Ma M, Zhao C, Danese N (2012). A method of applying linear seakeeping panel pressure to full ship structural models. Proceedings of $11^{\text {th }}$ International Conference on Computer Applications and Information Technology in the Maritime Industries, Liege, Belgium.

MAESTRO (2018). MAESTRO Version 11.6.0. MAESTRO Marine LLC, Greensboro, MD, USA.

Paik JK (2015). What will be the maximum size of container vessels?. New Horizons, Hyundai Heavy Industries Co. Ltd, South Korea, 32-33

Paik JK (2018). Ultimate limit state analysis and design of plated structures. $2^{\text {nd }}$ Edition, John Wiley \& Sons, Chichester, UK.

Paik JK (2019). Advanced structural safety studies with extreme and accidental events. Springer, New York, USA (to be published).

Prini F, Birminghan RW, Benson S, Phillips HJ, Sheppard PJ, Mediavilla Varas J, Johnson M, Dow RS (2016). Motions and loads of a high-speed craft in regular waves: prediction and analysis. Proceedings of $24^{\text {th }}$ International HISWA Symposium on Yacht Design and Yacht Construction, Amsterdam, The Netherlands.

Temarel P, Bai W, Bruns A, Derbanne Q, Dessi D, Dhavalikar S, Fonseca N, Fukasawa T, Gu X, Nestegård A, Papanikolaou A, Parunov J, Song KH, Wang S (2016). Prediction of wave-induced loads on ships: progress and challenges. Ocean Engineering, 119: 274-308.

Walck C (2007). Handbook on statistical distributions for experimentalists. International Report No. 
SUF-PFY/96-01, University of Stockholm, Stockholm, Sweden.

Youssef SAM, Paik JK (2018). Hazard identification and scenario selection of ship grounding accidents. Ocean Engineering, 153: 242-255.

Zhao C, Ma M, Hughes OF (2013). Applying strip theory based linear seakeeping loads to 3D full ship finite element models. Proceedings of the ASME $32^{\text {nd }}$ International Conference on Ocean, Offshore and Arctic Engineering, 9-14 June, Nantes, France.

Zhao C, Ma M (2016). A hybrid 2.5-dimensional high-speed strip theory method and its application to apply pressure loads to 3-dimensional full ship finite element models. Journal of Ship Production and Design, 32(4): 216-225. 